\title{
Making Sense of the Epigenome Using Data Integration Approaches
}

\author{
Emma Cazaly', Joseph Saad ${ }^{1}$, Wenyu Wang ${ }^{1}$, Caroline Heckman', Miina Ollikainen ${ }^{1,2 *}$ \\ and Jing Tang ${ }^{1,3,4 *}$
}

${ }^{1}$ Institute for Molecular Medicine Finland, Helsinki Institute of Life Science, University of Helsinki, Helsinki, Finland, ${ }^{2}$ Department of Public Health, University of Helsinki, Helsinki, Finland, ${ }^{3}$ Department of Mathematics and Statistics, University of Turku, Turku, Finland, ${ }^{4}$ Research Program in Systems Oncology, Faculty of Medicine, University of Helsinki, Helsinki, Finland

\section{OPEN ACCESS}

Edited by:

Chandravanu Dash

Meharry Medical College,

United States

Reviewed by:

Volker Martin Lauschke, Karolinska Institute (KI), Sweden

Zhiguo Xie,

Central South University, China

*Correspondence:

Miina Ollikainen

miina.ollikainen@helsinki.fi

Jing Tang

jing.tang@he/sinki.fi

Specialty section:

This article was submitted to

Pharmacogenetics

and Pharmacogenomics,

a section of the journal

Frontiers in Pharmacology

Received: 22 November 2018

Accepted: 31 January 2019

Published: 19 February 2019

Citation:

Cazaly E, Saad J, Wang W, Heckman C, Ollikainen M and Tang $J$

(2019) Making Sense of the

Epigenome Using Data Integration

Approaches

Front. Pharmacol. 10:126.

doi: 10.3389/fphar.2019.00126
Epigenetic research involves examining the mitotically heritable processes that regulate gene expression, independent of changes in the DNA sequence. Recent technical advances such as whole-genome bisulfite sequencing and affordable epigenomic arraybased technologies, allow researchers to measure epigenetic profiles of large cohorts at a genome-wide level, generating comprehensive high-dimensional datasets that may contain important information for disease development and treatment opportunities. The epigenomic profile for a certain disease is often a result of the complex interplay between multiple genetic and environmental factors, which poses an enormous challenge to visualize and interpret these data. Furthermore, due to the dynamic nature of the epigenome, it is critical to determine causal relationships from the many correlated associations. In this review we provide an overview of recent data analysis approaches to integrate various omics layers to understand epigenetic mechanisms of complex diseases, such as obesity and cancer. We discuss the following topics: (i) advantages and limitations of major epigenetic profiling techniques, (ii) resources for standardization, annotation and harmonization of epigenetic data, and (iii) statistical methods and machine learning methods for establishing data-driven hypotheses of key regulatory mechanisms. Finally, we discuss the future directions for data integration that shall facilitate the discovery of epigenetic-based biomarkers and therapies.

Keywords: epigenetics, data integration, functional annotation, drug discovery, data resources, profiling techniques

\section{INTRODUCTION}

Complex diseases and traits have a genetic background, yet the final phenotypic outcome largely depends on an individual's environment and lifestyle, and genomic studies have thus far explained only a small fraction of the inherited risk of many complex diseases (Eichler et al., 2010). This missing heritability may in part be explained by the contribution of epigenetic variation to complex diseases. Moreover, the majority of genetic variants associated with a disease risk are located at non-coding regions of the genome, suggesting that these SNPs point to genomic regions with a downstream regulatory role. It is well-established that cells regulate gene expression during multiple stages of transcription and translation, predominantly through chromatin packaging (Holliday, 2006). Chromatin is a complex of DNA and DNA binding proteins that control the packaging of DNA and thereby affect the access of transcription factors to the regulatory regions 
of genes. This process is regulated by two epigenetic mechanisms: dynamic DNA methylation and post-translational modifications of DNA binding histone proteins.

DNA methylation plays an important role in silencing tissuespecific genes, imprinted genes and repetitive elements (Walsh et al., 1998; Fouse et al., 2008). DNA methylation in human cells occurs predominantly at the cytosine of a cytosine-guanine pair (CpG dinucleotide), where a methyl group is covalently attached to the carbon 5 position. In the human genome there are approximately 28 million $\mathrm{CpG}$ dinucleotides, accounting for $1 \%$ of the whole genome. Of these, 60 to $90 \%$ are methylated, while the majority of unmethylated sites cluster non-randomly in regions called $\mathrm{CpG}$ islands (CGIs). CGIs co-localize to the promoter region of up to $70 \%$ of human genes (Illingworth and Bird, 2009). In general, unmethylated CGIs are associated with transcriptionally permissive chromatin and gene expression. During normal development and in certain disease states, particularly in cancer, these CGIs can become methylated, leading to inhibition of transcription factor binding and gene repression.

In addition to DNA methylation (5mC), DNA hydroxymethylation $(5 \mathrm{hmC})$ is another essential epigenetic modification in cells. Hydroxymethylation is the primary product of the oxidation of 5-methylcytosine by the ten-eleven translocation (TET) enzymes. In this process methylated cytosine $(5 \mathrm{mC})$ is first oxidized into 5-hydroxymethylcytosine (5hmC), then to 5-formylcytosine and to 5-carboxylcytosine $(5 \mathrm{caC})$. These are removed by thymine DNA glycosylase and replaced by unmethylated cytosine by base excision repair. However, hydroxymethylation is not merely an intermediate of the dynamic demethylation process but actually a temporarily stable epigenetic modification of DNA (Globisch et al., 2010). Hydroxymethylated cytosines are enriched at the promoters and enhancers of developmental genes, and they correlate positively with gene expression during cell lineage commitment in early development. In addition, hydroxymethylation is present in gene bodies of actively transcribed genes (Colquitt et al., 2013; Tsagaratou et al., 2014; Nestor et al., 2016). Hydroxymethylation is less abundant than DNA methylation, and its abundance varies between tissues and cell types. It is more abundant in embryonic stem cells (Ito et al., 2010), and human brain tissue $(0.67 \%)$, kidney $(0.38 \%)$, colon $(0.45 \%)$, rectum $(0.57 \%)$, and liver $(0.46 \%)$, while low or very low in human lung, breast and placenta (Li and Liu, 2011). The abundance of hydroxymethylation seems to be inversely correlated with the proliferation rate of a cell (Kriaucionis and Heintz, 2009; Bachman et al., 2014). The dynamic interplay between DNA methylation and hydroxymethylation is presumably important for maintaining normal gene expression patterns in a cell, however, the causes and consequences of the imbalance between these two DNA modifications is still to be understood.

In contrast to DNA methylation and hydroxymethylation, which are set de novo at early embryogenesis and maintained during DNA replication, histone modifications are posttranslational changes. They act to remodel the chromatin structure and regulate gene expression through chromatin accessibility (ENCODE Project Consortium, 2012). Histone modifications are the largest category of chromatin modifications identified so far, with 15 known chemical modifications at more than 130 sites on 5 canonical histones and on around 30 histone variants. Specific histone modification patterns often correlate with known functional genomic elements. For example, $\mathrm{H} 3 \mathrm{~K} 9 \mathrm{me} 3$ and $\mathrm{H} 3 \mathrm{~K} 27 \mathrm{me} 3$ are associated with inactive promoters; while $\mathrm{H} 3 \mathrm{~K} 4 \mathrm{me} 3$ and $\mathrm{H} 3 \mathrm{~K} 27 \mathrm{ac}$ are shown to be enriched in active enhancers and promoters (Karlic et al., 2010; Zhou V.W. et al., 2011). However, the theoretical number of all possible histone - modification combinations is huge, particularly when compared to the extremely limited knowledge on their functional roles.

An additional layer of epigenetic regulation is derived from non-coding RNA (ncRNA), which is transcribed from DNA but not translated into protein. NcRNA ranges from very small 22 nucleotide microRNA molecules (miRNA), to transcripts longer than 200 nucleotides (lncRNA). NcRNAs play a role in translation, splicing, DNA replication and gene regulation, particularly through miRNA directed downregulation of gene expression (Valencia-Sanchez et al., 2006). NcRNAs are most widely studied in the context of cancer, where they have been identified in the tumor suppressor or oncogenic processes of all major cancers (Anastasiadou et al., 2018). The techniques for measuring ncRNA are similar to other transcriptomic techniques, predominantly involving deep sequencing approaches (Veneziano et al., 2016). In recent years it has become apparent that there is a coordinated interaction between ncRNA and other epigenetic marks, the extent of which is yet to be fully realized (Ferreira and Esteller, 2018). The discovery of more than 100 post-transcriptional modifications to ncRNA, such as methylated adenines and cytosines, is providing further insight into the interaction between these different epigenetic layers (Romano et al., 2018). For the latest advances in the ncRNA biology, we refer the reader to the special series in Nature Reviews Genetics, January 1st $2018^{1}$.

DNA methylation (referring to both $5 \mathrm{mC}$ and $5 \mathrm{hmC}$ from here on), histone modifications and ncRNA respond to genetic and environmental effects and thereby alter gene expression, providing biological mechanisms for the development of common diseases. Therefore, epigenetic mechanisms are key to understanding disease progression and discovering new treatment targets (Lord and Cruchaga, 2014). As one of the more recent omics fields, epigenomics has experienced rapid growth in the past decade, providing novel insights to many areas of cell biology. Recent developments in microarray technology have made the generation of genome-wide epigenetic data feasible in large populations (Pidsley et al., 2016). As such, epigenome-wide association studies (EWASs) have become an important component of omics-driven approaches to investigate the origin of common human traits and diseases (Lappalainen and Greally, 2017).

Despite the tremendous potential to improve our understanding of disease progression and treatment, epigenetics has yet to become fully utilized in clinical applications. Similar to transcriptomics, epigenetic profiles are continuous, dynamic and tissue-specific. As ever more epigenetic data are generated

\footnotetext{
${ }^{1}$ https://www.nature.com/collections/sqtqxdnvdz
} 
with advances in high-throughput sequencing and microarray technologies, the challenges now become developing data analysis approaches to facilitate the identification of coordinated epigenetic changes and interpretation of their functional consequences in normal development and disease. For example, an effective data annotation protocol is needed for a communitydriven data standardization to improve the replicability of epigenetic findings (Carter et al., 2017). In particular, the variation in epigenetics profiles at different time points is yet to be established as a control for the reference in normal populations. Partly due to the lack of appropriate and efficient computational methods, the majority of existing studies focus on a single epigenetic mark in isolation, although the interactions of multiple marks and genotypes exist in vivo (Davila-Velderrain et al., 2015). To realize the full potential offered by epigenetics, an interdisciplinary research community is needed to foster effective and robust data integration strategies for combining epigenetics data with other omics data (Figure 1).

In the following sections we will review the recent advances in computational methods and applications for epigenomic analysis and discovery, ranging from databases and software tools for statistical analysis to data integration techniques for functional annotation. We will start by comparing the common epigenomic profiling technologies, before moving on to data annotation and standardization models. We then provide an overview of various data sources leveraged in epigenetic studies and their applications. We describe statistical and machine learning methods to pinpoint epigenetic modifications driving disease, and provide a list of software tools capable of implementing these methods, as well as databases containing epigenomic and other omics data. This catalog provides a comprehensive and practical resource to build data-driven hypotheses for analyzing the functional consequences of epigenetic marks. Finally, we provide representative examples of profiling epigenetics in disease states and its significance in biomarker and drug discovery.

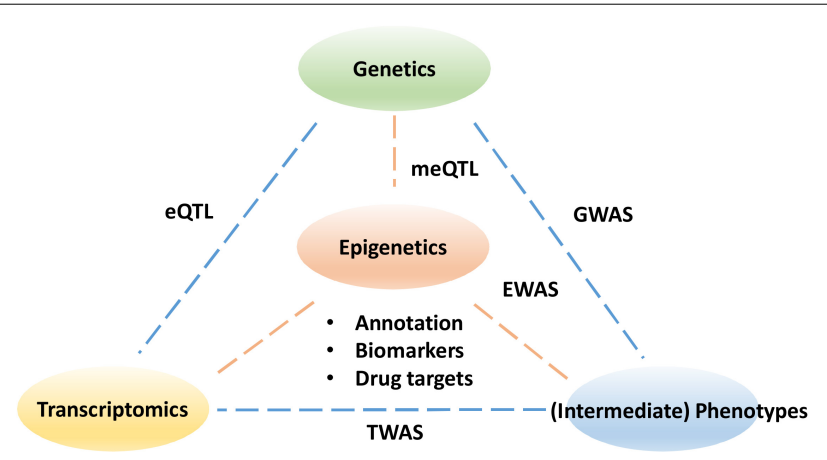

FIGURE 1 | The pillars to understanding the functional impact of epigenetics data. The epigenetic links need to be made with sequence variants in genetics as well as changes in transcriptomics. Understanding the impact of epigenetics on intermediate phenotypes for example metabolomics and proteomics may ultimately help explain the disease etiology and help drug discovery. GWASs, genome-wide association studies; EWASs, epigenome wide association studies; meQTL, methylation quantitative trait loci; eQTL, expression quantitative trait loci; TWAS, transcriptome-wide association study.

\section{EPIGENETIC PROFILING TECHNIQUES}

Epigenetic analysis techniques can be broadly classified as typing, involving a small number of loci across many samples, or profiling that can be extended to epigenomewide analysis. The end-point measurements from these methods often reflect a proportion or ratio of chromatin with epigenetic marks compared to the total chromatin. Within these categories, various sequencing, microarray and antibody based methodologies are employed to examine the different aspects of epigenetic regulation, including DNA methylation, chromatin accessibility and histone modifications. Epigenetic data generated from these techniques require different pre-processing steps depending on the methodology employed. For example, array-based DNA methylation analysis requires extensive within and between array normalization, preprocessing and integration across platforms (Fortin et al., 2017), while bisulfite sequencing can be processed with a relatively standardized sequence trimming and alignment pipeline (Wreczycka et al., 2017). Further complications include the feasibility of using epigenetic profiles derived from blood as a proxy for other less accessible tissue types (Houseman et al., 2015), and controlling for tumor purity in cancer studies (Zheng et al., 2017). Here, we summarize the most common epigenetic profiling techniques and compare their advantages and limitations (Tables 1, 2).

\section{DATA RESOURCES FOR STANDARDIZATION, ANNOTATION, AND HARMONIZATION}

Unlike the human genome, the epigenome varies across different cell types and over time. Due to recent efforts in big data consortia, such as the Encyclopedia of DNA Elements (ENCODE) (Davis et al., 2018) and the International Human Epigenome Consortium (IHEC) (Bujold et al., 2016), genome-wide epigenetic reference datasets are now publically available for different cell lineages, tissues, and diseases. Within IHEC, standardization of sample preparation and assay protocols have been benchmarked and implemented across multiple centers, that have been collected from seven international consortia including ENCODE, NIH Roadmap (Bernstein et al., 2010), Blueprint (Martens and Stunnenberg, 2013) and others across Europe, North America, and Asia. Furthermore, efficient data portal infrastructure has provided powerful tools for interactive exploration and annotation of the resulting datasets at a genomewide scale, encompassing over 800 reference epigenomes for different tissues and conditions. Such a communitydriven profiling effort has provided rich resources and tools for future epigenetic data mining and functional annotation. More recently, these datasets have been made available via the Human Epigenome Browser (Zhou X. et al., 2011), providing the visualization tools similar to the UCSC Genome Browser (Kent et al., 2002). Here, we 
list the common data repositories and their visualization tools (Table 3).

To facilitate the sharing of epigenomic data between different studies, standardization of sample preparation and assay protocols is required. While there are existing recommendations for reporting the minimal information to annotate omics studies such as MIAME for gene expression data and MIAPE for proteomics data, the consensus for the annotation protocol for epigenetics data has yet to be defined. This is partly due to the versatile techniques for various epigenetic features

TABLE 1 | Summary of major profiling techniques for DNA methylation.

\begin{tabular}{|c|c|c|c|}
\hline Technique & Method & Advantages & Limitations \\
\hline $\begin{array}{l}\text { Whole-Genome Bisulfite Sequencing } \\
\text { (WGBS) }\end{array}$ & $\begin{array}{l}\text { Bisulfite converted DNA is amplified } \\
\text { and sequenced }\end{array}$ & $\begin{array}{l}\text { Genome-wide, single nucleotide } \\
\text { resolution }\end{array}$ & Costly and computationally intensive \\
\hline $\begin{array}{l}\text { Reduced-Representation Bisulfite } \\
\text { Sequencing (RRBS) }\end{array}$ & $\begin{array}{l}\text { Methylation-insensitive restriction } \\
\text { enzymes digest DNA, enriching for } \\
\text { CpG regions }\end{array}$ & $\begin{array}{l}\text { Cheaper than WGBS with relatively high } \\
\text { coverage }\end{array}$ & $\begin{array}{l}\text { Enzymatic digestion covers most but } \\
\text { not all CpG sites }\end{array}$ \\
\hline Pyrosequencing & $\begin{array}{l}\text { DNA is bisulfite converted, amplified, } \\
\text { with the ratio of } \mathrm{C} / \mathrm{T} \text { nucleotides } \\
\text { measured }\end{array}$ & $\begin{array}{l}\text { Genome-wide or targeted, single } \\
\text { nucleotide resolution. Allele-specific } \\
\text { primers }\end{array}$ & Relatively expensive \\
\hline $\begin{array}{l}\text { Methylated DNA Immunoprecipitation } \\
\text { (MeDip) }\end{array}$ & $\begin{array}{l}\text { Methylated DNA is enriched by } \\
\text { immunoprecipitation followed by } \\
\text { sequencing or microarray analysis }\end{array}$ & $\begin{array}{l}\text { Random fragmentation by sonication } \\
\text { avoids restriction enzyme bias }\end{array}$ & $\begin{array}{l}\text { Varying CpG density can confound } \\
\text { methylation estimates }\end{array}$ \\
\hline $\begin{array}{l}\text { Methylation Sensitive Restriction } \\
\text { Enzyme Sequencing (MSRE/MRE-Seq } \\
\text { or Methyl-seq) }\end{array}$ & $\begin{array}{l}\text { Unmethylated DNA is restriction } \\
\text { enzyme digested while methylated DNA } \\
\text { is amplified }\end{array}$ & No bisulfite conversion bias & $\begin{array}{l}\text { DNA may be partially digested, limited } \\
\text { coverage }\end{array}$ \\
\hline $\begin{array}{l}\text { Combined Bisulfite Restriction Analysis } \\
\text { (COBRA) }\end{array}$ & $\begin{array}{l}\text { Bisulfite converted DNA is amplified } \\
\text { and restriction enzyme digested }\end{array}$ & $\begin{array}{l}\text { Simple, fast, inexpensive, works on } \\
\text { FFPE-treated DNA }\end{array}$ & $\begin{array}{l}\text { DNA may be partially digested, limited } \\
\text { coverage }\end{array}$ \\
\hline Methylation Specific PCR & $\begin{array}{l}\text { Bisulfite converted DNA is amplified } \\
\text { with methylation specific primers }\end{array}$ & Simple and inexpensive & Purely qualitative \\
\hline High Resolution Melt Analysis (HRM) & $\begin{array}{l}\text { Bisulfite converted DNA is amplified by } \\
\text { q-PCR }\end{array}$ & $\begin{array}{l}\text { Most sensitive method for determining } \\
\text { methylation at a specific region }\end{array}$ & Single base resolution not possible \\
\hline $\begin{array}{l}\text { Illumina MethylationEPIC BeadChip } \\
\text { Microarray (previously 450k, 27k) }\end{array}$ & $\begin{array}{l}\text { Bisulfite (or oxidized + bisulfite) } \\
\text { converted DNA is interrogated on a } \\
\text { microarray chip }\end{array}$ & $\begin{array}{l}\text { Relatively simple and inexpensive. } \\
\text { Extremely popular }\end{array}$ & $\begin{array}{l}\text { Data has limited coverage and requires } \\
\text { pre-processing }\end{array}$ \\
\hline Global DNA Methylation & $\begin{array}{l}\text { Methods include LINE1, Alu, LUMA, } \\
\text { HPLC-UV }\end{array}$ & Relatively inexpensive & $\begin{array}{l}\text { Does not identify differentially } \\
\text { methylated regions }\end{array}$ \\
\hline $\begin{array}{l}\text { Tet-assisted Bisulfite Sequencing } \\
\text { (TAB-seq) }\end{array}$ & $\begin{array}{l}5 \mathrm{hmC} \text { is protected then oxidized to } \\
5 \mathrm{caC} \text { then uracil by TET }\end{array}$ & $\begin{array}{l}\text { Differentiation between } 5 \mathrm{mC} \text { and } 5 \mathrm{hmC} \\
\text { at single base resolution }\end{array}$ & $\begin{array}{l}\text { Sensitivity and specificity depends on } \\
\text { sequencing depth }\end{array}$ \\
\hline Oxidative Bisulfite Sequencing (OxBis) & $\begin{array}{l}\text { DNA is oxidized then bisulfite converted } \\
\text { to } 5 f C \text { and subsequently uracil }\end{array}$ & Quantitative genome-wide coverage & $\begin{array}{l}\text { Bias to regions of low } 5 \mathrm{mC} \text {. Must be } \\
\text { performed in parallel with bisulfite } \\
\text { techniques }\end{array}$ \\
\hline $\begin{array}{l}\text { APOBEC-coupled epigenetic } \\
\text { sequencing (ACE-seq) }\end{array}$ & $\begin{array}{l}\text { Non-destructive DNA deaminase } \\
\text { enzymes discriminate between } 5 \mathrm{hmC} \\
\text { and } 5 \mathrm{mC}\end{array}$ & $\begin{array}{l}\text { Genome-wide, single nucleotide } \\
\text { resolution. Very low DNA input required }\end{array}$ & Not yet extensively tested \\
\hline $\begin{array}{l}\text { Hydroxymethylated DNA } \\
\text { Immunoprecipitation (hMeDIP) }\end{array}$ & $\begin{array}{l}\text { Immunoprecipitation and sequencing of } \\
\text { hydroxymethylated DNA }\end{array}$ & Simple and inexpensive & $\begin{array}{l}\text { Only semi quantitative and bias to } \\
\text { regions of low } 5 \mathrm{hmC}\end{array}$ \\
\hline
\end{tabular}

TABLE 2 | Summary of major profiling techniques for Chromatin Accessibility and Histone modifications.

\begin{tabular}{|c|c|c|c|}
\hline Technique & Method & Advantages & Limitations \\
\hline Chromatin Immunoprecipitation (ChIP) & $\begin{array}{l}\text { Couples highly specific antibodies for } \\
\text { DNA-binding proteins with sequencing, } \\
\text { microarrays or PCR }\end{array}$ & $\begin{array}{l}\text { Detect DNA associated proteins and } \\
\text { histone modifications }\end{array}$ & Requires intact cells and chromatin \\
\hline Digital DNase & $\begin{array}{l}\text { Enzymes digest nuclease-accessible } \\
\text { regions, indicating open chromatin }\end{array}$ & $\begin{array}{l}\text { Maps both nucleosomes and } \\
\text { non-histone proteins }\end{array}$ & $\begin{array}{l}\text { High sequencing depth required. } \\
\text { Potential actin contamination. }\end{array}$ \\
\hline NOMe-seq & $\begin{array}{l}\text { Single-molecule, high-resolution } \\
\text { nucleosome positioning assay }\end{array}$ & $\begin{array}{l}\text { Maps both DNA methylation and } \\
\text { nucleosomes at high resolution }\end{array}$ & Relies on presence of $\mathrm{CpG}$ residues \\
\hline $\begin{array}{l}\text { Assay for Transposase-Accessible } \\
\text { Chromatin using sequencing } \\
\text { (ATAC-seq) }\end{array}$ & $\begin{array}{l}\text { Measures chromatin accessibility based } \\
\text { on Tn5 transposase activity. Maps } \\
\text { nucleosomes and non-histone proteins }\end{array}$ & $\begin{array}{l}\text { Simple, fast, low input of cells with } \\
\text { single nucleotide resolution }\end{array}$ & $\begin{array}{l}\text { Distance between binding sites may } \\
\text { bias results }\end{array}$ \\
\hline $\begin{array}{l}\text { Chromosome Conformation Capture } \\
(3 \mathrm{C}, 4 \mathrm{C}, 5 \mathrm{C}, \mathrm{Hi}-\mathrm{C})\end{array}$ & $\begin{array}{l}\text { Assess spatial organization of } \\
\text { chromatin in a cell }\end{array}$ & Various modified versions & $\begin{array}{l}\text { Often lack genome-wide, single } \\
\text { nucleotide resolution }\end{array}$ \\
\hline
\end{tabular}


that require distinctive experimental protocols for achieving optimal results (Chervitz et al., 2011). To improve the data interoperability, comparisons of the epigenetics profiling techniques have been initiated by the international consortia. For example, the BLUEPRINT consortium has conducted a systematic comparison of different DNA methylation profiling technologies and reported generally consistent results, whilst also highlighting the higher performance of sequencing-based assays over array-based or antibody-based assays (BLUEPRINT Consortium, 2016). Moreover, informatics approaches such as APIs (Application Programming Interfaces) have been developed to extract data from different repositories in a more efficient manner. One example is the DeepBlue web server, which provides an API for retrieving major epigenetic studies of IHEC (Albrecht et al., 2016). The use of resource description framework (RDF) such as Bio2RDF has also been proposed to allow for the sharing of knowledge to facilitate text mining techniques for information retrieval (Jupp et al., 2014).

\section{STATISTICAL AND DATA INTEGRATION METHODS FOR INTERROGATING THE EPIGENOME}

As is the case in association studies in other fields, EWAS detect epigenetic marks associated with a certain phenotype. Common epigenetic study designs include case-control studies,

TABLE 3 | Epigenetic data repositories and browsers.

\begin{tabular}{|c|c|c|}
\hline Consortia and resources & Data availability & URLs \\
\hline $\begin{array}{l}\text { The International Human Epigenome } \\
\text { Consortium (IHEC) }\end{array}$ & $\begin{array}{l}\text { Reference epigenomes generated by NIH Roadmap, } \\
\text { ENCODE, CEEHRC, BLUEPRINT, DEEP, } \\
\text { AMED/CREST, and KEP }\end{array}$ & IHEC Data Portal http://epigenomesportal.ca/ihec \\
\hline NIH Roadmap Epigenomics & $\begin{array}{l}\text { Maps of histone modifications, chromatin accessibility, } \\
\text { DNA methylation and mRNA Expression in stem cells } \\
\text { and primary ex vivo human tissues }\end{array}$ & VizHub http://vizhub.wustl.edu \\
\hline $\begin{array}{l}\text { Canadian Epigenetics, Environment and Health } \\
\text { Research Consortium (CEEHRC) Network }\end{array}$ & $\begin{array}{l}\text { Reference epigenomes including histone modifications, } \\
\text { DNA methylation, mRNA and miRNA of human cancer } \\
\text { and normal cells }\end{array}$ & $\begin{array}{l}\text { CEEHRC Data http://www.epigenomes.ca/site-data } \\
\text { Software Tools } \\
\text { http://www.epigenomes.ca/tools-and-software }\end{array}$ \\
\hline BLUEPRINT Epigenome & $\begin{array}{l}\text { Reference epigenomes of human normal and malignant } \\
\text { hematopoietic cells }\end{array}$ & BLUEPRINT Portal http://blueprint-data.bsc.es \\
\hline The German epigenome programme (DEEP) & $\begin{array}{l}\text { Reference epigenomes of human cells and tissues in } \\
\text { normal and complex disease states }\end{array}$ & DEEP Data Portal http://deep.dkfz.de \\
\hline IHEC Team Japan (AMED-CREST) & $\begin{array}{l}\text { Reference epigenomes of human gastrointestinal } \\
\text { epithelial cells, vascular endothelial cells and cells of } \\
\text { reproductive organs }\end{array}$ & IHEC Data Portal http://epigenomesportal.ca/ihec \\
\hline Korea Epigenome Project (KEP) & $\begin{array}{l}\text { Reference epigenome map for common complex } \\
\text { diseases }\end{array}$ & IHEC Data Portal http://epigenomesportal.ca/ihec \\
\hline DeepBlue & $\begin{array}{l}\text { Epigenomic data server for storing and working with } \\
\text { genomic and epigenomic data. Collection of over } \\
\text { 30,000 experiment files from the main epigenome } \\
\text { mapping projects available. Uploading own data } \\
\text { allowed }\end{array}$ & DeepBlue server http://deepblue.mpi-inf.mpg.de \\
\hline Allelic Epigenome Project & $\begin{array}{l}\text { Allelic DNA methylome, histone modifications, and } \\
\text { transcriptome in human cells and tissues }\end{array}$ & $\begin{array}{l}\text { Genboree http: } \\
\text { //genboree.org/genboreeKB/projects/allelic-epigenome }\end{array}$ \\
\hline GTEx & $\begin{array}{l}\text { Genotype and expression profiles in different tissues } \\
\text { enabling eQTL studies }\end{array}$ & GTEx Portal http://www.gtexportal.org \\
\hline BRAINEAC & $\begin{array}{l}\text { Brain eQTL Almanac provides genotype and expression } \\
\text { profile across } 10 \text { brain regions }\end{array}$ & BRAINEAC http://braineac.org \\
\hline MQTLdb & $\begin{array}{l}\text { Methylation and genotype data on mother-child pairs } \\
\text { providing access to meQTL mapping across five } \\
\text { different stages of life }\end{array}$ & mQTL Database http://www.mqtldb.org \\
\hline Fetal brain meQTLs & $\begin{array}{l}\text { Epigenome-wide significant meQTLs observed in fetal } \\
\text { brain }\end{array}$ & $\begin{array}{l}\text { Fetal Brain meQTL } \\
\text { http://epigenetics.essex.ac.uk/mQTL }\end{array}$ \\
\hline Pancan-meQTL & $\begin{array}{l}\text { Database of cis- and trans- meQTLs across } 23 \text { cancer } \\
\text { types from The Cancer Genome Atlas }\end{array}$ & $\begin{array}{l}\text { Pancan-meQTL } \\
\text { http://bioinfo.life.hust.edu.cn/Pancan-meQTL }\end{array}$ \\
\hline Epigenome Browser & $\begin{array}{l}\text { UCSC genome browser with tracks from ENCODE } \\
\text { project }\end{array}$ & $\begin{array}{l}\text { UCSC Epigenome Browser } \\
\text { http://www.epigenomebrowser.org }\end{array}$ \\
\hline WashU Epigenome Browser & $\begin{array}{l}\text { Web browser with tracks from ENCODE and Roadmap } \\
\text { Epigenomics projects }\end{array}$ & $\begin{array}{l}\text { WashU Epigenome Browser } \\
\text { http://epigenomegateway.wustl.edu }\end{array}$ \\
\hline Ensembl & ENCODE data used in the regulatory build & Ensembl ENCODE https://www.ensembl.org \\
\hline RMBase & Database listing over 100 RNA modifications & http://rna.sysu.edu.cn/rmbase/ \\
\hline
\end{tabular}


cross-sectional or longitudinal cohort studies, and family or twin designs. Logistic regression is commonly used for a case vs. control or binomial phenotype design, while linear regression is employed with continuous phenotypes. Technical and biological covariates are added to the regression models to adjust for confounding factors in the data and methods that control the false discovery rate posed by multiple testing are applied.

The resulting epigenetic profiles can be visualized on appropriate web tools, such as UCSC Genome Browser (Kent et al., 2002), EpiGenome Browser (Zhou X. et al., 2011), or coMET (Martin et al., 2015). While recent advances in epigenetic profiling techniques have made EWAS more cost-efficient and effective, interpreting the results from such epigenomic studies remains a challenge. Without a careful selection of tissues and population samples, many EWAS associations may partly stem from the dynamic and complex nature of the interactions between the different epigenetic layers, or arise from the fact that epigenetic states differ spatially across tissues and cell types as well as during aging. Therefore, there have been significant difficulties inferring the causality of epigenetic marks among a range of genetic, environmental and stochastic factors. A variety of data integration approaches, such as co-mapping and network analysis are currently employed to unravel the complexities of these various epigenetic layers and their interaction with other omics datasets (Hasin et al., 2017).

In this section we discuss data integration approaches for the functional annotation of trait-associated epigenetic hits by the use of knowledge bases, by predicting chromatin states, and by establishing associations with gene expression. Alternatively, the genetic basis of DNA methylation marks can be studied using the meQTL analyses, from which computational tools can be utilized to further identify the potential functional variants. The results of robust associations between genetic variants, epigenetics marks and disease traits can be integrated in the framework of causal modeling, with an aim to dissect causal epigenetic marks from those that are secondary to disease progression. These likely causal epigenetic marks may be further developed into potential disease biomarkers and drug targets upon experimental investigation, for example using epigenome editing techniques.

\section{Functional Annotation Pathways}

Genes and their regulators do not function in isolation, but are organized into pathways and networks. To obtain a more holistic view on the potential functional implications of the EWAS hits, multiple tools on gene ontologies (GOs), pathway and network analysis are available for researchers to interpret their findings. For example, GO biological process, molecular function, and cellular component pathways of the EWAS hits can be explored by PANTHER (protein annotation through evolutionary relationship) tools (Mi et al., 2013). Other commonly used tools include Gene Set Enrichment Analysis (GSEA) (Subramanian et al., 2005), where a predefined set of genes represent a pathway collected from multiple databases such as KEGG (Kyoto Encyclopedia of Genes and Genomes) (Kanehisa et al., 2017). The commercial Ingenuity Pathway
Analysis (IPA ${ }^{\odot}$ QIAGEN) can be also used to examine biological networks, functions, and associated diseases (Kramer et al., 2014). In addition to these gene centered analyses, genome region enrichment analysis has been proposed to infer the functional significance of the epigenetic marks at potential regulatory elements. For example, the LOLA tool can test a non-coding genomic region of interest for overlap with curated region set databases (Sheffield and Bock, 2016). The GREAT tool (Genomic Regions Enrichment of Annotations Tool) associates cis-regulatory regions identified by, e.g., ChIP-seq with biological processes by computing the enrichment scores for a given ontology term of the nearby genes (McLean et al., 2010). As a result, insights into the functional significance of the cisregulatory regions across the genome are produced.

\section{Chromatin States}

To infer the chromatin states from epigenetics data, networkbased methods such as hidden Markov model (HMM) have been developed to determine the probability of chromatin states at different genomic regions from the histone modification marks (de Pretis and Pelizzola, 2014). Notably, a widely applied method is ChromHMM which can efficiently learn the hidden chromatin states based on the distinctive combinatorial and spatial patterns of histone modification marks (Ernst and Kellis, 2017). These data-driven chromatin states are then annotated by their putative functions, such as transcription start sites, enhancers or promoters. Annotating the genome with such predicted chromatin states together with other genomic information may reveal functional elements, particularly for those regions that are in linkage disequilibrium (LD) with disease-associated SNPs. ChromHMM has been implemented in an ENCODE study to integrate 14 epigenetic marks, including histone modifications, transcription factors and chromatin accessibility for 6 human cell types, resulting in 25 chromatin states that are predictive of RNA transcription (Hoffman et al., 2013). The resulting gene regulatory elements mapped by these computational methods from ENCODE and other consortium projects have allowed individual researchers to interrogate and interpret their EWAS findings. Furthermore, computational methods that aim to predict tissue or cell-type specific functional regions have been proposed. For example, a web-based tool eFORGE (experimentally derived Functional element Overlap analysis of ReGions from EWAS) can be used to inform which traitassociated methylation hits are likely functional in a given tissue or cell type. The eFORGE method computes an enrichment score based on the overlap between the CpG sites of interest and DNase I hypersensitive sites (as marks for active chromatin) to predict the functionality of a $\mathrm{CpG}$ site in a given cell type, and thus help prioritize the EWAS results in terms of functional impact (Breeze et al., 2016). Another complementary method called dCMA is based on differential chromatin modification analysis to identify cell-type specific regulatory elements from ChIP-Seq data (Chen et al., 2013).

\section{Gene Expression}

The association between epigenetic marks and gene expression has been extensively studied to identify the functional 
consequences of epigenetic marks identified in an EWAS. This is commonly accomplished by linear regression models with the expression level of a gene as the dependent variable and CpG site methylation or histone modification as the independent variable. Adjusting for biological and technical confounders is also common practice in such models, which can be used to explore how epigenetic marks interact with gene expression throughout the genome. For example, a recent study in human blood cells applied a linear mixed effects model, by which DNA methylation signatures for more than $13 \mathrm{k}$ transcripts were defined (Kennedy et al., 2018).

While the association between CGI promoter methylation and gene expression is well-established and readily interpretable (Cedar and Bergman, 2012), the regulatory role of DNA methylation outside CGIs, in 'shores' and 'shelves' and throughout gene bodies is less extensively studied. However, methylation in these regions is potentially more relevant to diseases, as these are the regions that vary the most between tissue types and between cancerous and normal tissue (Irizarry et al., 2009). Unlike promoter methylation which is associated with gene repression, the association between intragenic methylation and gene expression is more bell-curved, with high methylation associated with moderately expressed genes and low methylation observed in genes with either high or low expression (Jjingo et al., 2012). This complex relationship between DNA methylation and gene expression poses challenges for comprehensively integrating gene expression and DNA methylation data. Public databases such as the Gene Expression Omnibus $\left(\mathrm{GEO}^{2}\right)$ can also be employed to assist in the interpretation of EWAS findings. Inferring causal relationships between DNA methylation and gene expression can be obtained by including genetic data in the models, as discussed in the next two sections.

\section{Identification of Genetic Drivers of Epigenetic Marks}

One of the major objectives in epigenetic studies is to identify SNPs that are associated with DNA methylation marks as meQTLs. In order to demonstrate whether trait-associated DNA methylation is independent of genetic variants influencing methylation, a regression analysis can be conducted using for example R package MatrixEQTL (Shabalin, 2012). Results of meQTL analyses include a ranked list of both short distance cis and more distal ( $>1 \mathrm{Mb}$ from the DNA methylation site) trans effects of genetic variants on DNA methylation. Public repositories such as the mQTLdb database (Gaunt et al., 2016) and BIOS QTL browser (Bonder et al., 2017) are invaluable in epigenetic research as they enable the results from largescale individual studies to be incorporated in subsequent meta analyses. Recently, meta-databases have been developed to systematically curate, harmonize and integrate meQTL data across different diseases. For example, Pancan-meQTL provides the result of meQTLs for 23 cancer types (Gong et al., 2018). The findings of meQTL analyses can be coupled with eQTL results in interpreting GWAS hits, as demonstrated in a recent study which identified a strong correlation between meQTLs

\footnotetext{
${ }^{2}$ https://www.ncbi.nlm.nih.gov/geo/
}

and eQTLs that are shared by common genetic variants from peripheral blood (Pierce et al., 2018). Similar conclusions have been made in a study involving 3,841 Dutch individuals, where disease-associated variants have been found to affect both transcription factor levels and methylation of their binding sites (Bonder et al., 2017).

Integrating epigenetic marks with genotypes can also aid in interpreting the functionality of trait-associated SNPs observed in GWAS. Therefore, computational tools to predict the functions of genetic variants can be also used for annotating the functional consequences of meQTLs. Information that has been generally considered in such prediction tasks includes sequence conservation, population frequency as well as functional genomics. Approaches such as SIFT (Kumar et al., 2009) and PolyPhen2 (Adzhubei et al., 2013) align human protein sequences to homologous sequences from the other organisms to evaluate the impact of missense variants. Such sequence conservation approaches have been extended to identify conserved elements in non-coding regions by PhastCons (Siepel et al., 2005) and GERP (Davydov et al., 2010). In comparison, tools such as VAAST also utilize population frequency information from large consortiums, i.e., the 1000 Genome project for variant prioritization. Moreover, machine learning technology has long been introduced into the functional annotation of genetic variants (see Holder et al., 2017 for a recent review). For example, the PANTHER method utilizes a HMM to capture the relationship between sequence similarity and functional similarity, based on which the functional impact of a given genetic variant can be predicted (Thomas et al., 2003). As one of the most widely used methods, the CADD method employed epigenomic information such as genomic regions of DNase I hypersensitivity and histone modifications as predictive features to train the Supported Vector Machine to predict the causal variants in the genomic regions (Rentzsch et al., 2019).

\section{Dissecting Causality by Mendelian Randomization and Causal Networks}

While many of the above-mentioned methods help illustrate the various functions of trait -associated epigenetic marks, it is often difficult to distinguish cause from consequence. In addition, the associations are often confounded by other factors. Mendelian randomization (MR) is a special form of causal network modeling, where the causality between a potential risk factor and an outcome can be established by including the genotype data (Tang et al., 2009; Latvala and Ollikainen, 2016). To be able to establish whether an association between an epigenetic mark and a disease outcome is causal, MR utilizes a series of statistical inference rules, which start by identifying an instrumental variable from the trait-associated genetic variants. This genetic instrument must fulfill the following criteria: (1) associated with the exposure, (2) independent of any potential confounders, and (3) associated with the outcome of interest only via its association with the exposure. Since the genetic variant occurs at germline that precedes the onset of disease, reverse causality is not possible. Also, as parental alleles are randomly segregated and assorted to offspring, associations between genetic 
variation and the outcome of interest are unlikely to be affected by confounding factors. The principles and recent developments in MR are described in detail elsewhere (Davey Smith and Ebrahim, 2003; Davey Smith and Hemani, 2014).

Mendelian randomization has been commonly used in epidemiology, and has recently been applied to infer causality in epigenetics studies as well. Depending on the applications, epigenetics marks have been considered as either the exposure or the outcome of interest in the MR model. For example, Relton and Davey Smith provided a two-step MR framework to select the instrument variables for both the risk factors and the DNA methylation marks, so that the causality cascade from the risk factors to the disease outcome can be established (Relton and Davey Smith, 2012). Such a two-step MR framework has been recently applied to study the causal roles of DNA methylation between smoking and inflammation (Jhun et al., 2017). On the other hand, a similar stepwise MR framework has been applied to distinguish causal effects from associations between blood lipid levels and DNA methylation, where the blood lipid levels were considered as the risk factor to affect DNA methylation of white blood cells (Dekkers et al., 2016). More recently, a systematic MR study involved multiple steps to investigate the meQTLs as the instrumental variables to understand the causal effect of DNA methylation for a large variety of disease traits (Richardson et al., 2018). As a validation, majority of the candidate loci were known to affect gene expression and DNA methylation, and thus supported the validity of MR as a datadriven approach to generate plausible biological hypotheses that warrant further experimental investigation. The basic version of MR involves the use of bivariate analysis, which can be extended as a causal network inference that involves the testing of multiple instrument variables in relation to different risk factors and disease outcomes. For example, the joint likelihood method (JLIM) tests whether two risk factors share the same causal genetic variants by evaluating the similarity of LD patterns between the SNPs, which is a form of co-localization methods (Chun et al., 2017). The other co-localization methods include HEIDI (heterogeneity in dependent instrument) (Zhu et al., 2016) and coloc (Giambartolomei et al., 2014) methods, while only summary-level data is used. More recently, a method called GSMR leveraged multiple SNPs as instrument variables to test for causality between risk factors and common diseases (Zhu et al., 2018).

Alternatives of causal modeling include the causal mediation analysis, which employs a series of hypothesis testing on the conditional independence among genetic variants, exposure, and disease traits (Millstein et al., 2009). The mediation analysis infers how much the indirect causal effect of an exposure on a disease outcome is mediated by a mediator, while MR focuses on the direct causal effect of the exposure on the disease outcome using a genetic variant as the proxy (Richmond et al., 2016a). A model-based causal mediation approach is available in the mediation R package (Imai et al., 2010), which has been applied in a recent study to identify nine potential epigenetic CpG sites that may mediate the effect of prenatal famine exposure to adult body mass index (BMI), serum triglycerides, and glucose levels. Notably, these CpG sites were all located at regulatory regions which are linked to the expression of growth, differentiation, and metabolism-related genes (Tobi et al., 2018).

For a model selection perspective, both causal mediation analysis and MR can be considered as special cases of causal network modeling, which compares the likelihoods for multiple competing models about causality (e.g., reverse causality model or confounding effect model) (Burgess et al., 2015). These different statistical frameworks to test for causality of epigenetic marks are useful tools, however, it is never possible to definitively prove causality based on these methods only. Instead, any negative or positive findings should be interpreted with caution and should be supported by multiple independent approaches with different assumptions, as well as the sensitivity analyses of the measurement error, and finally to match with the available biological knowledge and experimental validation (Hermani et al., 2017; Yarmolinsky et al., 2018).

\section{INTEGRATIVE APPROACHES TO UNDERSTAND THE ROLE OF EPIGENETICS IN COMPLEX TRAITS}

To date, 10s of 1000s of genetic variants have been associated with human complex traits via GWAS. Based on the findings of twin studies, these diseases and traits are, on average, 50\% heritable (Polderman et al., 2015). To be able to better explain the functions of the genetic variants, the field of epigenetics has been actively researched. Next, we will describe a few representative case studies in obesity and cancer, where the integration of genetic, epigenetic, and transcriptomic data has been a key component in understanding the disease etiology and progression. The information gained from such studies can then help inform future diagnostic biomarker and treatment strategies.

\section{Obesity and Associated Traits}

Numerous EWAS studies have shown that BMI and obesity are associated with widespread changes in DNA methylation, most often profiled using Illumina $450 \mathrm{~K}$ or EPIC arrays (Dick et al., 2014; Ollikainen et al., 2015; Pietilainen et al., 2016; Mendelson et al., 2017; Wahl et al., 2017; Davis et al., 2018; Dhana et al., 2018). Most of the findings are tissue specific, or shared by a few tissue types (Dick et al., 2014; Wahl et al., 2017), with some hits replicated between studies, while others appear to be more study or population specific. Many of the observed DNA methylation hits are at or near genes that have previously been related to BMI or obesity traits by genetic association, while others may reflect novel genes and pathways involved in the regulation of adiposity or obesity-related diseases (Ollikainen et al., 2015; Mendelson et al., 2017; Wahl et al., 2017).

Integration of DNA methylation data with predicted chromatin states from ENCODE data has revealed that the genomic regions associated with obesity by DNA methylation are often enriched for regulatory features (Ollikainen et al., 2015; Wahl et al., 2017). Potential functional consequences of the observed methylation alterations have been tested by correlating DNA methylation with gene expression of the nearby genes, and concomitant changes in DNA methylation and gene expression 
have been observed in many obesity relevant genes. Integration of DNA methylation with genotype data (as meQTLs) has been used to annotate GWAS hits, and to identify novel candidate obesity-associated genes. For example meQTLs at KLF13 (Koh et al., 2017) and MCR4 (Tang et al., 2017) have been shown to associate with childhood obesity. In addition to identification of meQTLs, integration of genotypes and DNA methylation can be used to infer causality in the observed associations, for example by MR -based approaches. These analyses have shown that the observed associations are predominantly the consequence of high BMI or obesity - related metabolic outcomes (Dick et al., 2014; Ollikainen et al., 2015; Richmond et al., 2016b; Wahl et al., 2017). However, NFATC2IP and SREBF1 methylation have been shown to have potential causal associations with BMI (Mendelson et al., 2017; Wahl et al., 2017). Finally, some studies have shown that the disturbances in DNA methylation predict future development of type 2 diabetes (Wahl et al., 2017) and coronary heart disease (Hedman et al., 2017), and that DNA methylation could be used to distinguish metabolically unhealthy from healthy obesity (Ollikainen et al., 2015; Wahl et al., 2017). To enable early detection of individuals with increased risk for metabolic complications, further studies are needed to thoroughly examine whether DNA-methylation could serve as a biomarker for metabolically unhealthy obesity.

Taken together, results from multiple epigenetic studies using data integration approaches in obesity and related traits may provide new insights into the biological pathways influenced by adiposity. Although most of the epigenetic changes are consequential to obesity or related traits, a few appear to have a causal role. Identification of causal hits is critical not only for understanding the biological mechanisms in the development of obesity and metabolic disturbances, but also for developing novel, effective prevention, and treatment strategies that target the underlying mechanisms. However, the cross-sectional nature of most of the analyzed data sets limits definitive causal determination. In addition, the marks that are caused by obesity can be considered as potential biomarkers of obesity or related metabolic disturbances. These may enable development of new strategies for prediction and prevention of adverse metabolic consequences of obesity.

\section{Cancer}

Despite the fact that cancer has been traditionally perceived as a genetic disease, epigenetic mechanisms have been increasingly identified to contribute to many hallmarks of cancer (Flavahan et al., 2017). Epigenetic alterations are shown to be responsible for the activation of cancer oncogenes or the inactivation of tumor suppressors (Kagohara et al., 2018). Numerous recent cancer epigenetics studies have demonstrated that data integration not only enables a more detailed understanding of disease mechanisms at the molecular level, but also offers novel insights on improved approaches for disease diagnostics, treatment, and management. For example, The Cancer Genome Atlas (TCGA) project has produced DNA methylation data for over 10000 cancer samples (Hoadley et al., 2014). Here, we highlight a few representative cancer epigenetic studies where a combination of multiple data analysis methods have been applied.
One case study implemented a genome-wide chromatin accessibility profiling for chronic lymphocytic leukemia (CLL) patient samples using ChIPmentation and RNA-seq profiling (Rendeiro et al., 2016). Using a Random Forest machine learning method (Rahman et al., 2017), it was found that epigenetic profiles can accurately predict the IGHV mutation status. Furthermore, common and constitutively accessible regions as well as regions with higher inter-individual variability were also found. Similar studies were done using reduced representation bisulfite sequencing (RRBS) for Ewing sarcoma, a rare cancer that is known to be caused by the EWS-FLI1 fusion gene. Despite the common genetic background, substantial DNA methylation differences between and within cancers were found (Sheffield et al., 2017). Notably, several computational tools have been developed in this study. For example, a MIRA score has been derived to transform the epigenetic state of a given genomic region into the degree of regulatory activity. Moreover, the intra-tumor heterogeneity has been measured using the PIM (proportion of sites with intermediate methylation) and PDR (proportion of discordant reads) scoring which can capture the cell-to-cell heterogeneity and the epigenetic instability within the tumor cells separately. The PIM score was then used to predict the metastatic state of a patient-derive sample using a logistic regression model.

Another study focused on triple-negative breast cancer (TNBC) by jointly contrasting the transcriptomic and epigenetic profiles of cancer stem cells (CSCs) versus non-cancer stem cells (NCSCs) (Li et al., 2018). Differentially expressed genes between CSCs and NCSCs were first identified by performing an RNA-Seq data preprocessing using tools including HTSeq (Anders et al., 2015) and samtools (Li et al., 2009), as well as differential analyses using $\mathrm{R}$ packages including DEGSeq (Wang et al., 2010). Subsequently, functional significance of cisregulatory regions were analyzed with the GREAT (McLean et al., 2010) for the identification of significantly disrupted signaling pathways. Furthermore, patterns of differential DNA methylation and histone modifications were analyzed. By performing a WGBS analysis, differentially-methylated $\mathrm{CpG}$ sites in promoter regions [defined around genes' transcription start sites (TSSs)] were identified using the methylKit $\mathrm{R}$ package (Akalin et al., 2012) and PeakAnalyzer (Salmon-Divon et al., 2010). In parallel, histone modifications were analyzed using ChIP-seq to determine and visualize different binding sites of antibodies specific to H3K4me2 (considered as a permissive mark for transcription) and H3K27me3 (a transcriptional silencer), using the R packages DiffBind (Ross-Innes et al., 2012) and seqMINER (Zhan and Liu, 2015). As a result, the repressive mark $\mathrm{H} 3 \mathrm{~K} 27 \mathrm{me} 3$ appeared to contribute more to the tumor-promoting tendencies of CSCs, notably by affecting melanogenesis, Wnt, and $\mathrm{GnRH}$ pathways, all of which are known to be involved in cellular proliferation and self-renewal, conferring to the typical characteristics of chemo- or radiotherapy- resistance.

In a study conducted on epithelial ovarian cancer (EOC), the integrated analysis of genetic (GWAS), expression (proteomic) and epigenetic (DNA methylation) data permitted the identification of a novel subtype-specific susceptibility gene for the malignancy (Shen et al., 2013). As a first step, a GWAS study 
for ovarian cancer (consisting of 43 smaller studies and a total of more than 16,000 EOC patients) identified various HNF1B SNPs for the serous and the clear cell subtypes of EOC. Specifically, while rs7405776 [minor allele frequency $(\mathrm{MAF})=36 \%$ ] was the most strongly associated SNP with serous EOC and conferred an increased risk of $13 \%$ per minor allele, rs11651755 (MAF $=45 \%)$ was strongly associated with the clear cell subtype of EOC and decreased the malignancy risk by $23 \%$ at genome-wide significance. This detection of HNF1B as a risk gene encouraged a more detailed evaluation of its promoter methylation profiles and its proteomic expression levels. An epigenetic silencing of HNF1B by DNA methylation was confirmed in half of the cases in the TCGA data including 576 primary serous EOC samples. To follow-up on the functional effects of the retained DNA methylation, a third cohort of 1149 EOC samples from the Ovarian Tumor Tissue Analysis (OTTA) Consortium (Bolton et al., 2012) was assessed. DNA-methylation analysis was also performed on 254 serous cases and 17 clear cell cases from those samples, using the Illumina $450 \mathrm{~K}$ assay, with plate normalization using a linear model on the logit-transformed beta values. The correlation between the gene expression and methylation was in line with the previous hypotheses, revealing a high $H N F 1 B$ expression and absence of promoter-methylation in most of the clear cell EOV samples, while the majority of serous samples displayed high promoter-methylation and stained negative for $H N F 1 B$ in the IHC assay. Such an integrated analysis involving multiple omics data provides strong evidence that different genetic or epigenetic variations within the $H N F 1 B$ gene can predispose to different histological variants of EOV, and that those variations could potentially be used as diagnostic tools for ovarian tumors.

\section{Epigenetics Biomarker and Drug Discovery}

Upon the validation of its functional role in the disease etiology, an epigenetic mark can be further developed as a diagnostic biomarker or a drug target. By definition, a biomarker is any characteristic that can be quantified and evaluated as an indicator of normal or pathogenic biological processes, or as a measure of response to some form of treatment. Biomarkers can take a wide variety of forms, including (but not limited to) genomic modifications, RNA transcripts, proteins, and/or epigenetic alterations (Costa-Pinheiro et al., 2015). Ideally, a suitable biomarker is a highly accurate one that can be obtained in a minimally invasive or non-invasive manner, which can be utilized for screening and detection methods, diagnosis and prognostication purposes, risk assessment, and/or for the prediction of response to therapy. Accordingly, epigenetic changes are considered among the most promising classes of cancer biomarkers, owing to their stability, potential reversibility, and ease of access. There are a few epigenetic biomarkers approved in non-invasive cancer diagnosis. For example, Cologuard has become the first FDA approved test for colorectal cancer (CRC) which involves the testing of DNA methylation levels at BMP3 and NDRG4, together with the mutation status of KRAS and hemoglobin. More recently FDA has approved a blood-based screening test for CRC called Epi procolon. The test measures the DNA methylation level of SEPT9, a gene that has been found to be hypermethylated in the promoter region (Issa and Noureddine, 2017).

Currently, a rich set of epigenetic biomarkers, including noncoding RNA expression levels, aberrant methylation patterns, and histone-modifying enzyme levels, are being tested in preclinical and clinical settings. For example, a urine-based epigenetic test on the DNA methylation of three genes (TWIST1, ONECTU2, and OTX1) in bladder cancer has achieved superior accuracy and now progressed to a larger validation study (Velazquez, 2018). Other potential epigenetic biomarkers include SHOX2 for lung cancer and BRCA1 for breast and ovarian cancers (Fece de la Cruz and Corcoran, 2018). To be able to leverage the existing cancer samples in the TCGA, a recent study developed a pancancer bisulfite sequencing assay to measure the methylation status of 9,223 GpG sites in plasma cell-free DNA in 34 major cancer types (Liu et al., 2018). The derived methylation signatures were then used for training a cancer type -specific classifier, each of which consisted of a unique set of $\mathrm{CpG}$ sites. The resulting classifier was used to predict the cancer type for a given sample, based solely on its methylation signature, demonstrating the feasibility of genome-wide epigenetic profiles for cancer diagnosis. In contrast, the development of epigenetics biomarkers in other disease areas is relatively in its early stage, with a few links being made for diabetes (Bacos et al., 2016) and schizophrenia (Rodrigues-Amorim et al., 2017).

In epigenetic drug discovery, histone post-translational modifications (PTMs) have been pursued as a major strategy as they constitute one of the most immediate contributors to epigenetic regulation. The PTM-affecting enzymes can be classified into three distinctive functional classes including writers, erasers and readers, which have been pursued as the targets for epigenetic drugs (Hyun et al., 2017). For example, cancer epigenetic therapy has focused on the development of targeted histone deacetylase (HDAC) inhibitors and DNA methyltransferase (DNMT) inhibitors. HDAC inhibitors activate histone acetylation, leading to higher expression of certain genes for apoptosis and cell cycle, while DNMT inhibitors re-activate tumor suppressor genes. The use of HDAC (e.g., vorinostat, belinostat, panobinostat, and romidepsin) and DNMT inhibitors (e.g., azacytidine and decitabine) has been approved for hematological malignancies. Furthermore, combinations of HDAC and DNMT inhibitors have shown synergistic interactions in a variety of cancer cell lines (Brocks et al., 2017).

In addition, overexpression and activity of histone methyltransferases (HMT) have been reported in a variety of cancers, notably acting via the silencing of essential tumorsuppressors (Bracken et al., 2003; Kim and Roberts, 2016). Consequently, HMT inhibitors such as tazemetostat and CPI-1205 have found their way to clinical development. It is unlikely that any single drug targeting epigenetic modifications is capable of curing a malignancy on its own. The combination with other such drug or with standard chemotherapeutic approaches offers the most promising prospects. For example, DNMT and HDAC inhibitors are thought to open up the chromatin conformation, thus rendering DNA more 
accessible to, and thereby more susceptible to damage, by chemotherapy. This observation has been validated by the successful combinations of azacitidine and low-dose cytarabine for AML (Radujkovic et al., 2014), or those of vorinostat and carboplatin or paclitaxel in non-small cell lung cancer (Owonikoko et al., 2010).

Other epigenetic modifiers that target the downstream proteins also have sparked interest. For example, the family of bromodomain containing proteins known as BETs have been involved in chromatin remodeling and transcriptional activity in a variety of diseases including inflammation, viral infection and cancer (Ferri et al., 2016). Furthermore, BET inhibition has been shown to decrease MYC expression and to restore normal cellular functions in a variety of cancers including hematological malignancies and solid tumors (Wang and Filippakopoulos, 2015). The first potent and selective BET inhibitor is the thienotiazolo-1,4-diazepine, known as the positive enantiomer $(+)$ of JQ1. Other BET inhibitors include I-BET762 which is currently being investigated in several ongoing clinical trials for different cancers (Andrieu et al., 2016).

\section{Pharmacoepigenetics}

Due to the lack of full annotations on the drug-induced epigenetic changes, the exact mode of action of the epigenetic drugs in different cancer cells remains largely unknown, which partly explains the individual variation in the clinical response (Treppendahl et al., 2014). On the other hand, it has been shown that many common drugs also induce epigenetic changes via the direct interaction with the PTM-affecting enzymes, or the downstream drug signaling pathways (Lotsch et al., 2013). These epigenetic changes may contribute to both the therapeutic and the adverse effects of the compounds, which are also mediated by the patient's individual genetic background, e.g., of drug-metabolizing enzymes and transporters. Only recently the concept of pharmacoepigenetics has started to emerge, aiming at the study of epigenetic mechanisms to explain the interindividual variability in drug responses (Majchrzak-Celińska and Baer-Dubowska, 2017; Lauschke et al., 2018). The epigenetic regulators of drug responses have been often linked to ADME (drug absorption, distribution, metabolism, and excretion) genes. For example, many genes in the Cytochrome P450 family are reported to be directly or indirectly regulated by miRNAs (Kim et al., 2014). Hypomethylation of the $A B C B 1$ promoter region has been shown to increase the gene's expression in cancer cells, leading to acquired drug resistance (Reed et al., 2010). Research in this field may eventually lead to the development of ADMErelated biomarkers for the stratification of patients into different treatment groups. In addition, epigenetic biomarkers that are not linked to ADME genes were also reported, while the exact mechanisms remain largely undetermined. In breast cancer for example, the quantification of PSAT1 DNA methylation is used to predict tamoxifen response (Martens et al., 2005; De Marchi et al., 2017), whereas that of BRCA1/2 (similarly to somatic mutations in those genes) is indicative of response to PARP inhibitors (Martens et al., 2005). Similarly, hypermethylation of MGMT and MLH1 correlates with increased response to 5-FU treatment and improved survival in CRC (Nagasaka et al., 2003; Jensen et al., 2013). Notably, a recent clinical study has discovered a DNA methylation signature to predict the response of Anti-Programmed Death-1 (PD-1) treatment for advanced non-small-cell lung cancer (Duruisseaux et al., 2018). Another clinical study called Genetic and Environmental Determinants of Triglycerides (GOLDN) measured the genetic and epigenetic profiles for metabolic syndrome using a familybased design (Aslibekyan et al., 2018). In this study, the epigenetic profiling was made before and after the treatment of fenofibrate, allowing the characterization of genotype and DNA methylation to understand the variability in the drug treatment response. Despite that potential biomarkers have been found in these recent advances, a systematic strategy to predict and understand the epigenome-wide interactions mediating the drug responses is still lacking. We anticipate that data integration methods as summarized in previous sections that are capable of annotating the epigenome from a pharmacological and pharmacokinetic perspective shall provide a valuable source of information to inform personalized treatment decisions.

\section{CONCLUSION}

Understanding epigenomic regulation is critical for dissecting gene-environment interactions in both normal development and disease. The fact that epigenetic profiles are plastic and reversible holds great promise for developing epigenetic biomarkers and drug targets. Furthermore, epigenetics captures the spatial and temporal variation on top of each individual's unique genome, and thus better informs the decision-making in personalized medicine. Recent developments have made chromatin accessibility profiling more cost-effective by allowing only a small number of cells as input, demonstrating the clinical potential of disease monitoring (Buenrostro et al., 2015). On the other hand, biobanks have made large scale clinical samples accessible and often provide functionality to share the accumulating raw data and molecular profiles similar to the concept of European Genome-Phenome Archive (EGA) (Lappalainen et al., 2015). Although individual epigenetic marks are often studied in isolation, the understanding of how the putative gene regulatory mechanisms occur will not be achieved without efficient tools to design, analyze, integrate, and interpret the versatile epigenetic features. To facilitate the systematic characterization of cells in a specific context, the other omics data such as transcriptomics and metabolomics may also provide complementary information to explain the interplay of the gene-environment interaction. Further developing the data integration tools shall more efficiently prioritize robust epigenetic modifications that are susceptible to environmental exposures and causal to specific diseases, so that specifically targeted compounds can be developed. Furthermore, despite the advances in these computational methods, one needs to ultimately resort to experimental approaches to confirm the hypothesis. The recent development of CRISPR-Cas9 and other genome editing tools may provide an efficient way to induce epigenetic alterations without the change of DNA sequences, so that novel drug targets 
and disease biomarkers may be identified more efficiently (Liao et al., 2017).

\section{AUTHOR CONTRIBUTIONS}

EC, $\mathrm{CH}, \mathrm{MO}$, and JT conceived the study. All authors participated the writing of the manuscript.

\section{REFERENCES}

Adzhubei, I., Jordan, D. M., and Sunyaev, S. R. (2013). Predicting functional effect of human missense mutations using PolyPhen-2. Curr. Protoc. Hum. Genet. 76, 7.20.1-7.20.41. doi: 10.1002/0471142905.hg0720s76

Akalin, A., Kormaksson, M., Li, S., Garrett-Bakelman, F. E., Figueroa, M. E., Melnick, A., et al. (2012). methylKit: a comprehensive R package for the analysis of genome-wide DNA methylation profiles. Genome Biol. 13:R87. doi: 10.1186/ gb-2012-13-10-r87

Albrecht, F., List, M., Bock, C., and Lengauer, T. (2016). DeepBlue epigenomic data server: programmatic data retrieval and analysis of epigenome region sets. Nucleic Acids Res. 44, W581-W586. doi: 10.1093/nar/gkw211

Anastasiadou, E., Jacob, L. S., and Slack, F. J. (2018). Non-coding RNA networks in cancer. Nat. Rev. Cancer 18, 5-18. doi: 10.1038/nrc.2017.99

Anders, S., Pyl, P. T., and Huber, W. (2015). HTSeq-a Python framework to work with high-throughput sequencing data. Bioinformatics 31, 166-169. doi: 10.1093/bioinformatics/btu638

Andrieu, G., Belkina, A. C., and Denis, G. V. (2016). Clinical trials for BET inhibitors run ahead of the science. Drug Discov. Today Technol. 19, 45-50. doi: 10.1016/j.ddtec.2016.06.004

Aslibekyan, S., Almasy, L., Province, M. A., Absher, D. M., and Arnett, D. K. (2018). Data for GAW20: genome-wide DNA sequence variation and epigenome-wide DNA methylation before and after fenofibrate treatment in a family study of metabolic phenotypes. BMC Proc. 12(Suppl. 9):35. doi: 10.1186/s12919-0180114-0

Bachman, M., Uribe-Lewis, S., Yang, X., Williams, M., Murrell, A., and Balasubramanian, S. (2014). 5-Hydroxymethylcytosine is a predominantly stable DNA modification. Nat. Chem. 6, 1049-1055. doi: 10.1038/nchem.2064

Bacos, K., Gillberg, L., Volkov, P., Olsson, A. H., Hansen, T., Pedersen, O., et al. (2016). Blood-based biomarkers of age-associated epigenetic changes in human islets associate with insulin secretion and diabetes. Nat. Commun. 7:11089. doi: $10.1038 /$ ncomms11089

Bernstein, B. E., Stamatoyannopoulos, J. A., Costello, J. F., Ren, B., Milosavljevic, A., Meissner, A., et al. (2010). The NIH roadmap epigenomics mapping consortium. Nat. Biotechnol. 28, 1045-1048. doi: $10.1038 /$ nbt1010-1045

BLUEPRINT Consortium (2016). Quantitative comparison of DNA methylation assays for biomarker development and clinical applications. Nat. Biotechnol. 34, 726-737. doi: 10.1038/nbt.3605

Bolton, K. L., Ganda, C., Berchuck, A., Pharaoh, P. D., and Gayther, S. A. (2012). Role of common genetic variants in ovarian cancer susceptibility and outcome: progress to date from the Ovarian Cancer Association Consortium (OCAC). J. Intern. Med. 271, 366-378. doi: 10.1111/j.1365-2796.2011.02509.x

Bonder, M. J., Luijk, R., Zhernakova, D. V., Moed, M., Deelen, P., Vermaat, M., et al. (2017). Disease variants alter transcription factor levels and methylation of their binding sites. Nat. Genet. 49, 131-138. doi: 10.1038/ng.3721

Bracken, A. P., Pasini, D., Capra, M., Prosperini, E., Colli, E., and Helin, K. (2003). $\mathrm{EZH} 2$ is downstream of the pRB-E2F pathway, essential for proliferation and amplified in cancer. EMBO J. 22, 5323-5335. doi: 10.1093/emboj/cdg542

Breeze, C. E., Paul, D. S., van Dongen, J., Butcher, L. M., Ambrose, J. C., Barrett, J. E., et al. (2016). eFORGE: a tool for identifying cell type-specific signal in epigenomic data. Cell Rep. 17, 2137-2150. doi: 10.1016/j.celrep.2016.10.059

Brocks, D., Schmidt, C. R., Daskalakis, M., Jang, H. S., Shah, N. M., Li, D., et al. (2017). DNMT and HDAC inhibitors induce cryptic transcription start sites encoded in long terminal repeats. Nat. Genet. 49, 1052-1060. doi: 10.1038/ng. 3889

\section{FUNDING}

This work has been supported by the European Research Council (ERC) starting grant agreement no. 716063 DrugComb to JT, Academy of Finland (Grant Nos. 317680 to JT, 297908 to MO), Sigrid Juselius Foundation to $\mathrm{MO}$ and University of Helsinki Research Funds to $\mathrm{MO}$.

Buenrostro, J. D., Wu, B., Chang, H. Y., and Greenleaf, W. J. (2015). ATAC-seq: a method for assaying chromatin accessibility genome-wide. Curr. Protoc. Mol. Biol. 109, 21.29.1-21.29.9. doi: 10.1002/0471142727.mb2129s109

Bujold, D., Morais, D. A. L., Gauthier, C., Cote, C., Caron, M., Kwan, T., et al. (2016). The international human epigenome consortium data portal. Cell Syst. 3, 496-499.e2. doi: 10.1016/j.cels.2016.10.019

Burgess, S., Daniel, R. M., Butterworth, A. S., Thompson, S. G., and Epic-InterAct Consortium (2015). Network mendelian randomization: using genetic variants as instrumental variables to investigate mediation in causal pathways. Int. J. Epidemiol. 44, 484-495. doi: 10.1093/ije/dyu176

Carter, A. C., Chang, H. Y., Church, G., Dombkowski, A., Ecker, J. R., Gil, E., et al. (2017). Challenges and recommendations for epigenomics in precision health. Nat. Biotechnol. 35, 1128-1132. doi: 10.1038/nbt.4030

Cedar, H., and Bergman, Y. (2012). Programming of DNA methylation patterns. Annu. Rev. Biochem. 81, 97-117. doi: 10.1146/annurev-biochem-052610091920

Chen, C., Zhang, S., and Zhang, X. S. (2013). Discovery of cell-type specific regulatory elements in the human genome using differential chromatin modification analysis. Nucleic Acids Res. 41, 9230-9242. doi: 10.1093/nar/ gkt712

Chervitz, S. A., Deutsch, E. W., Field, D., Parkinson, H., Quackenbush, J., RoccaSerra, P., et al. (2011). Data standards for omics data: the basis of data sharing and reuse. Methods Mol. Biol. 719, 31-69. doi: 10.1007/978-1-61779-027-0_2

Chun, S., Casparino, A., Patsopoulos, N. A., Croteau-Chonka, D. C., Raby, B. A., De Jager, P. L., et al. (2017). Limited statistical evidence for shared genetic effects of eQTLs and autoimmune-disease-associated loci in three major immune-cell types. Nat. Genet. 49, 600-605. doi: 10.1038/ng. 3795

Colquitt, B. M., Allen, W. E., Barnea, G., and Lomvardas, S. (2013). Alteration of genic 5-hydroxymethylcytosine patterning in olfactory neurons correlates with changes in gene expression and cell identity. Proc. Natl. Acad. Sci. U.S.A. 110, 14682-14687. doi: 10.1073/pnas.1302759110

Costa-Pinheiro, P., Montezuma, D., Henrique, R., and Jeronimo, C. (2015). Diagnostic and prognostic epigenetic biomarkers in cancer. Epigenomics 7, 1003-1015. doi: 10.2217/epi.15.56

Davey Smith, G., and Ebrahim, S. (2003). 'Mendelian randomization': can genetic epidemiology contribute to understanding environmental determinants of disease? Int. J. Epidemiol. 32, 1-22. doi: 10.1093/ije/dyg070

Davey Smith, G., and Hemani, G. (2014). Mendelian randomization: genetic anchors for causal inference in epidemiological studies. Hum. Mol. Genet. 23, R89-R98. doi: 10.1093/hmg/ddu328

Davila-Velderrain, J., Martinez-Garcia, J. C., and Alvarez-Buylla, E. R. (2015). Modeling the epigenetic attractors landscape: toward a post-genomic mechanistic understanding of development. Front. Genet. 6:160. doi: 10.3389/ fgene. 2015.00160

Davis, C. A., Hitz, B. C., Sloan, C. A., Chan, E. T., Davidson, J. M., Gabdank, I., et al. (2018). The encyclopedia of DNA elements (ENCODE): data portal update. Nucleic Acids Res. 46, D794-D801. doi: 10.1093/nar/gkx1081

Davydov, E. V., Goode, D. L., Sirota, M., Cooper, G. M., Sidow, A., and Batzoglou, S. (2010). Identifying a high fraction of the human genome to be under selective constraint using GERP++. PLoS Comput. Biol. 6:e1001025. doi: 10.1371/ journal.pcbi.1001025

De Marchi, T., Timmermans, M. A., Sieuwerts, A. M., Smid, M., Look, M. P., Grebenchtchikov, N., et al. (2017). Phosphoserine aminotransferase 1 is associated to poor outcome on tamoxifen therapy in recurrent breast cancer. Sci. Rep. 7:2099. doi: 10.1038/s41598-017-02296-w 
de Pretis, S., and Pelizzola, M. (2014). Computational and experimental methods to decipher the epigenetic code. Front. Genet. 5:335. doi: 10.3389/fgene.2014. 00335

Dekkers, K. F., van Iterson, M., Slieker, R. C., Moed, M. H., Bonder, M. J., van Galen, M., et al. (2016). Blood lipids influence DNA methylation in circulating cells. Genome Biol. 17:138. doi: 10.1186/s13059-016-1000-6

Dhana, K., Braun, K. V. E., Nano, J., Voortman, T., Demerath, E. W., Guan, W., et al. (2018). An epigenome-wide association Study (EWAS) of obesity-related traits. Am. J. Epidemiol. 187, 1662-1669. doi: 10.1093/aje/kwy025

Dick, K. J., Nelson, C. P., Tsaprouni, L., Sandling, J. K., Aissi, D., Wahl, S., et al. (2014). DNA methylation and body-mass index: a genome-wide analysis. Lancet 383, 1990-1998. doi: 10.1016/s0140-6736(13)62674

Duruisseaux, M., Martinez-Cardus, A., Calleja-Cervantes, M. E., Moran, S., Castro de Moura, M., Davalos, V., et al. (2018). Epigenetic prediction of response to anti-PD-1 treatment in non-small-cell lung cancer: a multicentre, retrospective analysis. Lancet Respir. Med. 6, 771-781. doi: 10.1016/s2213-2600(18)30284-4

Eichler, E. E., Flint, J., Gibson, G., Kong, A., Leal, S. M., Moore, J. H., et al. (2010). Missing heritability and strategies for finding the underlying causes of complex disease. Nat. Rev. Genet. 11, 446-450. doi: 10.1038/nrg2809

ENCODE Project Consortium (2012). An integrated encyclopedia of DNA elements in the human genome. Nature 489, 57-74. doi: 10.1038/nature11247

Ernst, J., and Kellis, M. (2017). Chromatin-state discovery and genome annotation with ChromHMM. Nat. Protoc. 12, 2478-2492. doi: 10.1038/nprot.2017.124

Fece de la Cruz, F., and Corcoran, R. B. (2018). Methylation in cell-free DNA for early cancer detection. Ann. Oncol. 29, 1351-1353. doi: 10.1093/annonc/ mdy 134

Ferreira, H. J., and Esteller, M. (2018). Non-coding RNAs, epigenetics, and cancer: tying it all together. Cancer Metastasis Rev. 37, 55-73. doi: 10.1007/s10555-0179715-8

Ferri, E., Petosa, C., and McKenna, C. E. (2016). Bromodomains: structure, function and pharmacology of inhibition. Biochem. Pharmacol. 106, 1-18. doi: 10.1016/j.bcp.2015.12.005

Flavahan, W. A., Gaskell, E., and Bernstein, B. E. (2017). Epigenetic plasticity and the hallmarks of cancer. Science 357:eaal2380. doi: 10.1126/science.aal2380

Fortin, J. P., Triche, T. J. Jr., and Hansen, K. D. (2017). Preprocessing, normalization and integration of the illumina HumanMethylationEPIC array with minfi. Bioinformatics 33, 558-560. doi: 10.1093/bioinformatics/btw691

Fouse, S. D., Shen, Y., Pellegrini, M., Cole, S., Meissner, A., Van Neste, L., et al. (2008). Promoter CpG methylation contributes to ES cell gene regulation in parallel with Oct4/Nanog, PcG complex, and histone H3 K4/K27 trimethylation. Cell Stem Cell 2, 160-169. doi: 10.1016/j.stem.2007.12.011

Gaunt, T. R., Shihab, H. A., Hemani, G., Min, J. L., Woodward, G., Lyttleton, O., et al. (2016). Systematic identification of genetic influences on methylation across the human life course. Genome Biol. 17:61. doi: 10.1186/s13059-0160926-z

Giambartolomei, C., Vukcevic, D., Schadt, E. E., Franke, L., Hingorani, A. D., Wallace, C., et al. (2014). Bayesian test for colocalisation between pairs of genetic association studies using summary statistics. PLoS Genet. 10:e1004383. doi: 10.1371/journal.pgen.1004383

Globisch, D., Munzel, M., Muller, M., Michalakis, S., Wagner, M., Koch, S., et al. (2010). Tissue distribution of 5-hydroxymethylcytosine and search for active demethylation intermediates. PLoS One 5:e15367. doi: 10.1371/journal.pone. 0015367

Gong, J., Wan, H., Mei, S., Ruan, H., Zhang, Z., Liu, C., et al. (2018). PancanmeQTL: a database to systematically evaluate the effects of genetic variants on methylation in human cancer. Nucleic Acids Res. 47, D1066-D1072. doi: 10.1093/nar/gky814

Hasin, Y., Seldin, M., and Lusis, A. (2017). Multi-omics approaches to disease. Genome Biol. 18:83. doi: 10.1186/s13059-017-1215-1

Hedman, ÅK., Mendelson, M. M., Marioni, R. E., Gustafsson, S., Joehanes, R., Irvin, M. R., et al. (2017). Epigenetic patterns in blood associated with lipid traits predict incident coronary heart disease events and are enriched for results from genome-wide association studies. Circ. Cardiovasc. Genet. 10:e01487. doi: 10.1161/CIRCGENETICS.116. 001487

Hermani, G., Tiling, K., and Davey Smith, G. (2017). Orienting the causal relationship between imprecisely measured traits using GWAS summary data. PLoS Genet. 13:e1007081. doi: 10.1371/journal.pgen.1007081
Hoadley, K. A., Yau, C., Wolf, D. M., Cherniack, A. D., Tamborero, D., Ng, S., et al. (2014). Multiplatform analysis of 12 cancer types reveals molecular classification within and across tissues of origin. Cell 158, 929-944. doi: 10.1016/ j.cell.2014.06.049

Hoffman, M. M., Ernst, J., Wilder, S. P., Kundaje, A., Harris, R. S., Libbrecht, M., et al. (2013). Integrative annotation of chromatin elements from encode data. Nucleic Acids Res. 41, 827-841. doi: 10.1093/nar/gks1284

Holder, L. B., Haque, M. M., and Skinner, M. K. (2017). Machine learning for epigenetics and future medical applications. Epigenetics 12, 505-514. doi: 10. 1080/15592294.2017.1329068

Holliday, R. (2006). Epigenetics: a historical overview. Epigenetics 1, 76-80. doi: 10.4161/epi.1.2.2762

Houseman, E. A., Kim, S., Kelsey, K. T., and Wiencke, J. K. (2015). DNA methylation in whole blood: uses and challenges. Curr. Environ. Health Rep. 2, 145-154. doi: 10.1007/s40572-015-0050-3

Hyun, K., Jeon, J., Park, K., and Kim, J. (2017). Writing, erasing and reading histone lysine methylations. Exp. Mol. Med. 49:e324. doi: 10.1038/emm.2017.11

Illingworth, R. S., and Bird, A. P. (2009). CpG islands-'a rough guide'. FEBS Lett. 583, 1713-1720. doi: 10.1016/j.febslet.2009.04.012

Imai, K., Keele, L., and Tingley, D. (2010). A general approach to causal mediation analysis. Psychol. Methods 15, 309-334. doi: 10.1037/a0020761

Irizarry, R. A., Ladd-Acosta, C., Wen, B., Wu, Z., Montano, C., Onyango, P., et al. (2009). The human colon cancer methylome shows similar hypo- and hypermethylation at conserved tissue-specific CpG island shores. Nat. Genet. 41, 178-186. doi: 10.1038/ng.298

Issa, I. A., and Noureddine, M. (2017). Colorectal cancer screening: an updated review of the available options. World J. Gastroenterol. 23, 5086-5096. doi: 10.3748/wjg.v23.i28.5086

Ito, S., D’Alessio, A. C., Taranova, O. V., Hong, K., Sowers, L. C., and Zhang, Y. (2010). Role of Tet proteins in $5 \mathrm{mC}$ to $5 \mathrm{hmC}$ conversion, ES-cell selfrenewal and inner cell mass specification. Nature 466, 1129-1133. doi: 10.1038/ nature09303

Jensen, L. H., Rasmussen, A. A., Byriel, L., Kuramochi, H., Cruger, D. G., Lindebjerg, J., et al. (2013). Regulation of MLH1 mRNA and protein expression by promoter methylation in primary colorectal cancer: a descriptive and prognostic cancer marker study. Cell Oncol. 36, 411-419. doi: 10.1007/s13402013-0148-2

Jhun, M. A., Smith, J. A., Ware, E. B., Kardia, S. L. R., Mosley, T. H Jr., Turner, S. T., et al. (2017). Modeling the causal role of DNA methylation in the association between cigarette smoking and inflammation in african americans: a 2-step epigenetic mendelian randomization study. Am. J. Epidemiol. 186, 1149-1158. doi: 10.1093/aje/kwx181

Jjingo, D., Conley, A. B., Yi, S. V., Lunyak, V. V., and Jordan, I. K. (2012). On the presence and role of human gene-body DNA methylation. Oncotarget 3, 462-474. doi: 10.18632/oncotarget.497

Jupp, S., Malone, J., Bolleman, J., Brandizi, M., Davies, M., Garcia, L., et al. (2014). The EBI RDF platform: linked open data for the life sciences. Bioinformatics 30, 1338-1339. doi: 10.1093/bioinformatics/btt765

Kagohara, L. T., Stein-O’Brien, G. L., Kelley, D., Flam, E., Wick, H. C., Danilova, L. V., et al. (2018). Epigenetic regulation of gene expression in cancer: techniques, resources and analysis. Brief. Funct. Genomics 17, 49-63. doi: 10. 1093/bfgp/elx018

Kanehisa, M., Furumichi, M., Tanabe, M., Sato, Y., and Morishima, K. (2017). KEGG: new perspectives on genomes, pathways, diseases and drugs. Nucleic Acids Res. 45, D353-D361. doi: 10.1093/nar/gkw1092

Karlic, R., Chung, H. R., Lasserre, J., Vlahovicek, K., and Vingron, M. (2010). Histone modification levels are predictive for gene expression. Proc. Natl. Acad. Sci. U.S.A. 107, 2926-2931. doi: 10.1073/pnas.0909344107

Kennedy, E. M., Goehring, G. N., Nichols, M. H., Robins, C., Mehta, D., Klengel, T., et al. (2018). An integrated -omics analysis of the epigenetic landscape of gene expression in human blood cells. BMC Genomics 19:476. doi: 10.1186/s12864018-4842-3

Kent, W. J., Sugnet, C. W., Furey, T. S., Roskin, K. M., Pringle, T. H., Zahler, A. M., et al. (2002). The human genome browser at UCSC. Genome Res. 12, 996-1006. doi: $10.1101 /$ gr.229102

Kim, I. W., Han, N., Burckart, G. J., and Oh, J. M. (2014). Epigenetic changes in gene expression for drug-metabolizing enzymes and transporters. Pharmacotherapy 34, 140-150. doi: 10.1002/phar.1362 
Kim, K. H., and Roberts, C. W. (2016). Targeting EZH2 in cancer. Nat. Med. 22, 128-134. doi: $10.1038 / \mathrm{nm} .4036$

Koh, I. U., Lee, H. J., Hwang, J. Y., Choi, N. H., and Lee, S. (2017). Obesity-related CpG methylation (cg07814318) of kruppel-like factor-13 (KLF13) gene with childhood obesity and its cis-methylation quantitative Loci. Sci. Rep. 7:45368. doi: $10.1038 /$ srep45368

Kramer, A., Green, J., Pollard, J. Jr., and Tugendreich, S. (2014). Causal analysis approaches in Ingenuity Pathway Analysis. Bioinformatics 30, 523-530. doi: 10.1093/bioinformatics/btt703

Kriaucionis, S., and Heintz, N. (2009). The nuclear DNA base 5hydroxymethylcytosine is present in Purkinje neurons and the brain. Science 324, 929-930. doi: 10.1126/science.1169786

Kumar, P., Henikoff, S., and Ng, P. C. (2009). Predicting the effects of coding nonsynonymous variants on protein function using the SIFT algorithm. Nat. Protoc. 4, 1073-1081. doi: 10.1038/nprot.2009.86

Lappalainen, I., Almeida-King, J., Kumanduri, V., Senf, A., Spalding, J. D., UrRehman, S., et al. (2015). The European Genome-phenome archive of human data consented for biomedical research. Nat. Genet. 47, 692-695. doi: 10.1038/ ng. 3312

Lappalainen, T., and Greally, J. M. (2017). Associating cellular epigenetic models with human phenotypes. Nat. Rev. Genet. 18, 441-451. doi: 10.1038/nrg.2017.32

Latvala, A., and Ollikainen, M. (2016). Mendelian randomization in (epi)genetic epidemiology: an effective tool to be handled with care. Genome Biol. 17:156. doi: 10.1186/s13059-016-1018-9

Lauschke, V. M., Barragan, I., and Ingelman-Sundberg, M. (2018). Pharmacoepigenetics and toxicoepigenetics: novel mechanistic insights and therapeutic opportunities. Annu. Rev. Pharmacol. Toxicol. 58, 161-185. doi: 10.1146/annurev-pharmtox-010617-053021

Li, G., Wang, D., Ma, W., An, K., Liu, Z., Wang, X., et al. (2018). Transcriptomic and epigenetic analysis of breast cancer stem cells. Epigenomics 10, 765-783. doi: 10.2217/epi-2018-0008

Li, H., Handsaker, B., Wysoker, A., Fennell, T., Ruan, J., Homer, N., et al. (2009). The sequence alignment/map format and SAMtools. Bioinformatics 25, 20782079. doi: 10.1093/bioinformatics/btp352

Li, W., and Liu, M. (2011). Distribution of 5-hydroxymethylcytosine in different human tissues. J. Nucleic Acids 2011:870726. doi: 10.4061/2011/870726

Liao, H. K., Hatanaka, F., Araoka, T., Reddy, P., Wu, M. Z., Sui, Y., et al. (2017). In vivo target gene activation via CRISPR/Cas9-mediated trans-epigenetic modulation. Cell 171, 1495-1507.e15. doi: 10.1016/j.cell.2017.10.025

Liu, L., Toung, J. M., Jassowicz, A. F., Vijayaraghavan, R., Kang, H., Zhang, R., et al. (2018). Targeted methylation sequencing of plasma cell-free DNA for cancer detection and classification. Ann. Oncol. 29, 1445-1453. doi: 10.1093/annonc/ mdy119

Lord, J., and Cruchaga, C. (2014). The epigenetic landscape of alzheimer's disease. Nat. Neurosci. 17, 1138-1140. doi: 10.1038/nn.3792

Lotsch, J., Schneider, G., Reker, D., Parnham, M. J., Schneider, P., Geisslinger, G., et al. (2013). Common non-epigenetic drugs as epigenetic modulators. Trends. Mol. Med. 19, 742-753. doi: 10.1016/j.molmed.2013.08.006

Majchrzak-Celińska, A., and Baer-Dubowska, W. (2017). Pharmacoepigenetics: an element of personalized therapy? Expert Opin. Drug Metab. Toxicol. 13, 387-398. doi: 10.1080/17425255.2017.1260546

Martens, J. H., and Stunnenberg, H. G. (2013). BLUEPRINT: mapping human blood cell epigenomes. Haematologica 98, 1487-1489. doi: 10.3324/haematol. 2013.094243

Martens, J. W., Nimmrich, I., Koenig, T., Look, M. P., Harbeck, N., Model, F., et al. (2005). Association of DNA methylation of phosphoserine aminotransferase with response to endocrine therapy in patients with recurrent breast cancer. Cancer Res. 65, 4101-4117. doi: 10.1158/0008-5472.Can-05-0064

Martin, T. C., Yet, I., Tsai, P. C., and Bell, J. T. (2015). coMET: visualisation of regional epigenome-wide association scan results and DNA co-methylation patterns. BMC Bioinformatics 16:131. doi: 10.1186/s12859-015-0568-2

McLean, C. Y., Bristor, D., Hiller, M., Clarke, S. L., Schaar, B. T., Lowe, C. B., et al. (2010). GREAT improves functional interpretation of cis-regulatory regions. Nat. Biotechnol. 28, 495-501. doi: 10.1038/nbt.1630

Mendelson, M. M., Marioni, R. E., Joehanes, R., Liu, C., Hedman, A. K., Aslibekyan, S., et al. (2017). Association of body mass index with DNA methylation and gene expression in blood cells and relations to cardiometabolic disease: a mendelian randomization approach. PLoS Med. 14:e1002215. doi: 10.1371/journal.pmed.1002215

Mi, H., Muruganujan, A., Casagrande, J. T., and Thomas, P. D. (2013). Large-scale gene function analysis with the panther classification system. Nat. Protoc. 8, 1551-1566. doi: 10.1038/nprot.2013.092

Millstein, J., Zhang, B., Zhu, J., and Schadt, E. E. (2009). Disentangling molecular relationships with a causal inference test. BMC Genet. 10:23. doi: 10.1186/14712156-10-23

Nagasaka, T., Sharp, G. B., Notohara, K., Kambara, T., Sasamoto, H., Isozaki, H., et al. (2003). Hypermethylation of O6-methylguanine-DNA methyltransferase promoter may predict nonrecurrence after chemotherapy in colorectal cancer cases. Clin. Cancer Res. 9, 5306-5312.

Nestor, C. E., Lentini, A., Hagg Nilsson, C., Gawel, D. R., Gustafsson, M., Mattson, L., et al. (2016). 5-Hydroxymethylcytosine remodeling precedes lineage specification during differentiation of human CD4(+) T cells. Cell Rep. 16, 559-570. doi: 10.1016/j.celrep.2016.05.091

Ollikainen, M., Ismail, K., Gervin, K., Kyllonen, A., Hakkarainen, A., Lundbom, J., et al. (2015). Genome-wide blood DNA methylation alterations at regulatory elements and heterochromatic regions in monozygotic twins discordant for obesity and liver fat. Clin. Epigenetics 7:39. doi: 10.1186/s13148-015-0073-5

Owonikoko, T. K., Ramalingam, S. S., Kanterewicz, B., Balius, T. E., Belani, C. P., and Hershberger, P. A. (2010). Vorinostat increases carboplatin and paclitaxel activity in non-small-cell lung cancer cells. Int. J. Cancer 126, 743-755. doi: 10.1002/ijc.24759

Pidsley, R., Zotenko, E., Peters, T. J., Lawrence, M. G., Risbridger, G. P., Molloy, P., et al. (2016). Critical evaluation of the Illumina MethylationEPIC beadchip microarray for whole-genome DNA methylation profiling. Genome Biol. 17:208. doi: 10.1186/s13059-016-1066-1

Pierce, B. L., Tong, L., Argos, M., Demanelis, K., Jasmine, F., Rakibuz-Zaman, M., et al. (2018). Co-occurring expression and methylation QTLs allow detection of common causal variants and shared biological mechanisms. Nat. Commun. 9:804. doi: 10.1038/s41467-018-03209-9

Pietilainen, K. H., Ismail, K., Jarvinen, E., Heinonen, S., Tummers, M., Bollepalli, S., et al. (2016). DNA methylation and gene expression patterns in adipose tissue differ significantly within young adult monozygotic BMI-discordant twin pairs. Int. J. Obes. 40, 654-661. doi: 10.1038/ijo.2015.221

Polderman, T. J., Benyamin, B., de Leeuw, C. A., Sullivan, P. F., van Bochoven, A., Visscher, P. M., et al. (2015). Meta-analysis of the heritability of human traits based on fifty years of twin studies. Nat. Genet. 47, 702-709. doi: 10.1038/ng. 3285

Radujkovic, A., Dietrich, S., Bochtler, T., Kramer, A., Schoning, T., Ho, A. D., et al. (2014). Azacitidine and low-dose cytarabine in palliative patients with acute myeloid leukemia and high bone marrow blast counts-a retrospective single-center experience. Eur. J. Haematol. 93, 112-117. doi: 10.1111/ejh.12308

Rahman, R., Otridge, J., and Pal, R. (2017). IntegratedMRF: random forest-based framework for integrating prediction from different data types. Bioinformatics 33, 1407-1410. doi: 10.1093/bioinformatics/btw765

Reed, K., Hembruff, S. L., Sprowl, J. A., and Parissenti, A. M. (2010). The temporal relationship between $\mathrm{ABCB} 1$ promoter hypomethylation, ABCB1 expression and acquisition of drug resistance. Pharmacogenomics J. 10, 489-504. doi: 10. 1038/tpj.2010.1

Relton, C. L., and Davey Smith, G. (2012). Two-step epigenetic Mendelian randomization: a strategy for establishing the causal role of epigenetic processes in pathways to disease. Int. J. Epidemiol. 41, 161-176. doi: 10.1093/ije/ dyr233

Rendeiro, A. F., Schmidl, C., Strefford, J. C., Walewska, R., Davis, Z., Farlik, M., et al. (2016). Chromatin accessibility maps of chronic lymphocytic leukaemia identify subtype-specific epigenome signatures and transcription regulatory networks. Nat. Commun. 7:11938. doi: 10.1038/ncomms11938

Rentzsch, P., Witten, D., Cooper, G. M., Shendure, J., and Kircher, M. (2019). CADD: predicting the deleteriousness of variants throughout the human genome. Nucleic Acids Res. 47, D886-D894. doi: 10.1093/nar/gky1016

Richardson, T. G., Haycock, P. C., Zheng, J., Timpson, N. J., Gaunt, T. R., Davey Smith, G., et al. (2018). Systematic Mendelian randomization framework elucidates hundreds of $\mathrm{CpG}$ sites which may mediate the influence of genetic variants on disease. Hum. Mol. Genet. 27, 3293-3304. doi: 10.1093/hmg/ ddy 210 
Richmond, R. C., Hemani, G., Tilling, K., Davey Smith, G., and Relton, C. L. (2016a). Challenges and novel approaches for investigating molecular mediation. Hum. Mol. Genet. 25, R149-R156. doi: 10.1093/hmg/ddw197

Richmond, R. C., Sharp, G. C., Ward, M. E., Fraser, A., Lyttleton, O., McArdle, W. L., et al. (2016b). DNA methylation and BMI: investigating identified methylation sites at HIF3A in a causal framework. Diabetes Metab. Res. Rev. 65, 1231-1244. doi: 10.2337/db15-0996

Rodrigues-Amorim, D., Rivera-Baltanas, T., Lopez, M., Spuch, C., Olivares, J. M., and Agis-Balboa, R. C. (2017). Schizophrenia: a review of potential biomarkers. J. Psychiatr. Res. 93, 37-49. doi: 10.1016/j.jpsychires.2017.05.009

Romano, G., Veneziano, D., Nigita, G., and Nana-Sinkam, S. P. (2018). RNA methylation in ncRNA: classes, detection, and molecular associations. Front. Genet. 9:243. doi: 10.3389/fgene.2018.00243

Ross-Innes, C. S., Stark, R., Teschendorff, A. E., Holmes, K. A., Ali, H. R., Dunning, M. J., et al. (2012). Differential oestrogen receptor binding is associated with clinical outcome in breast cancer. Nature 481, 389-393. doi: 10.1038/ nature 10730

Salmon-Divon, M., Dvinge, H., Tammoja, K., and Bertone, P. (2010). PeakAnalyzer: genome-wide annotation of chromatin binding and modification loci. BMC Bioinformatics 11:415. doi: 10.1186/1471-2105-11-415

Shabalin, A. A. (2012). Matrix eQTL: ultra fast eQTL analysis via large matrix operations. Bioinformatics 28, 1353-1358. doi: 10.1093/bioinformatics/bts163

Sheffield, N. C., and Bock, C. (2016). LOLA: enrichment analysis for genomic region sets and regulatory elements in $\mathrm{R}$ and Bioconductor. Bioinformatics 32, 587-589. doi: 10.1093/bioinformatics/btv612

Sheffield, N. C., Pierron, G., Klughammer, J., Datlinger, P., Schonegger, A., Schuster, M., et al. (2017). DNA methylation heterogeneity defines a disease spectrum in Ewing sarcoma. Nat. Med. 23, 386-395. doi: 10.1038/nm.4273

Shen, H., Fridley, B. L., Song, H., Lawrenson, K., Cunningham, J. M., Ramus, S. J., et al. (2013). Epigenetic analysis leads to identification of HNF1B as a subtype-specific susceptibility gene for ovarian cancer. Nat. Commun. 4:1628. doi: $10.1038 /$ ncomms2629

Siepel, A., Bejerano, G., Pedersen, J. S., Hinrichs, A. S., Hou, M., Rosenbloom, K., et al. (2005). Evolutionarily conserved elements in vertebrate, insect, worm, and yeast genomes. Genome Res. 15, 1034-1050. doi: 10.1101/gr.3715005

Subramanian, A., Tamayo, P., Mootha, V. K., Mukherjee, S., Ebert, B. L., Gillette, M. A., et al. (2005). Gene set enrichment analysis: a knowledge-based approach for interpreting genome-wide expression profiles. Proc. Natl. Acad. Sci. U.S.A. 102, 15545-15550. doi: 10.1073/pnas.0506580102

Tang, J., Tan, C. Y., Oresic, M., and Vidal-Puig, A. (2009). Integrating post-genomic approaches as a strategy to advance our understanding of health and disease. Genome Med. 1:35. doi: 10.1186/gm35

Tang, Y., Jin, B., Zhou, L., and Lu, W. (2017). MeQTL analysis of childhood obesity links epigenetics with a risk SNP rs17782313 near MC4R from meta-analysis. Oncotarget 8, 2800-2806. doi: 10.18632/oncotarget.13742

Thomas, P. D., Campbell, M. J., Kejariwal, A., Mi, H., Karlak, B., Daverman, R., et al. (2003). Panther: a library of protein families and subfamilies indexed by function. Genome Res. 13, 2129-2141. doi: 10.1101/gr.772403

Tobi, E. W., Slieker, R. C., Luijk, R., Dekkers, K. F., Stein, A. D., Xu, K. M., et al. (2018). DNA methylation as a mediator of the association. Sci. Adv. 4:eaao4364. doi: 10.1126/sciadv.aao4364

Treppendahl, M. B., Kristensen, L. S., and Gronbaek, K. (2014). Predicting response to epigenetic therapy. J. Clin. Invest. 124, 47-55. doi: 10.1172/jci69737

Tsagaratou, A., Aijo, T., Lio, C. W., Yue, X., Huang, Y., Jacobsen, S. E., et al. (2014). Dissecting the dynamic changes of 5-hydroxymethylcytosine in T-cell development and differentiation. Proc. Natl. Acad. Sci. U.S.A. 111, E3306E3315. doi: 10.1073/pnas.1412327111
Valencia-Sanchez, M. A., Liu, J., Hannon, G. J., and Parker, R. (2006). Control of translation and mRNA degradation by miRNAs and siRNAs. Genes Dev. 20, 515-524. doi: 10.1101/gad.1399806

Velazquez, N. (2018). Bladder cancer academy 2018 selected summaries. Rev. Urol. 20, 31-37. doi: 10.3909/riu02001BCA

Veneziano, D., Di Bella, S., Nigita, G., Lagana, A., Ferro, A., and Croce, C. M. (2016). Noncoding RNA: current deep sequencing data analysis approaches and challenges. Hum. Mutat. 37, 1283-1298. doi: 10.1002/humu.23066

Wahl, S., Drong, A., Lehne, B., Loh, M., Scott, W. R., Kunze, S., et al. (2017). Epigenome-wide association study of body mass index, and the adverse outcomes of adiposity. Nature 541, 81-86. doi: 10.1038/nature20784

Walsh, C. P., Chaillet, J. R., and Bestor, T. H. (1998). Transcription of IAP endogenous retroviruses is constrained by cytosine methylation. Nat. Genet. 20, 116-117. doi: 10.1038/2413

Wang, C. Y., and Filippakopoulos, P. (2015). Beating the odds: bets in disease. Trends Biochem. Sci. 40, 468-479. doi: 10.1016/j.tibs.2015.06.002

Wang, L., Feng, Z., Wang, X., Wang, X., and Zhang, X. (2010). DEGseq: an $\mathrm{R}$ package for identifying differentially expressed genes from RNA-seq data. Bioinformatics 26, 136-138. doi: 10.1093/bioinformatics/btp612

Wreczycka, K., Gosdschan, A., Yusuf, D., Gruning, B., Assenov, Y., and Akalin, A. (2017). Strategies for analyzing bisulfite sequencing data. J. Biotechnol. 261, 105-115. doi: 10.1016/j.jbiotec.2017.08.007

Yarmolinsky, J., Wade, K. H., Richmond, R. C., Langdon, R. J., Bull, C. J., Tilling, K. M., et al. (2018). Causal inference in cancer epidemiology: what is the role of mendelian randomization? Cancer Epidemiol. Biomarkers Prev. 27, 995-1010. doi: 10.1158/1055-9965.EPI-17-1177

Zhan, X., and Liu, D. J. (2015). Seqminer: an R-package to facilitate the functional interpretation of sequence-based associations. Genet. Epidemiol. 39, 619-623. doi: 10.1002/gepi.21918

Zheng, X., Zhang, N., Wu, H. J., and Wu, H. (2017). Estimating and accounting for tumor purity in the analysis of DNA methylation data from cancer studies. Genome Biol. 18:17. doi: 10.1186/s13059-016-1143-5

Zhou, V. W., Goren, A., and Bernstein, B. E. (2011). Charting histone modifications and the functional organization of mammalian genomes. Nat. Rev. Genet. 12, 7-18. doi: 10.1038/nrg2905

Zhou, X., Maricque, B., Xie, M., Li, D., Sundaram, V., Martin, E. A., et al. (2011). The human epigenome browser at washington university. Nat. Methods 8, 989-990. doi: 10.1038/nmeth.1772

Zhu, Z., Zhang, F., Hu, H., Bakshi, A., Robinson, M. R., Powell, J. E., et al. (2016). Integration of summary data from GWAS and eQTL studies predicts complex trait gene targets. Nat. Genet. 48, 481-487. doi: 10.1038/ng.3538

Zhu, Z., Zheng, Z., Zhang, F., Wu, Y., Trzaskowski, M., Maier, R., et al. (2018). Causal associations between risk factors and common diseases inferred from GWAS summary data. Nat. Commun. 9:224. doi: 10.1038/s41467-017-02 317-2

Conflict of Interest Statement: The authors declare that the research was conducted in the absence of any commercial or financial relationships that could be construed as a potential conflict of interest.

Copyright (c) 2019 Cazaly, Saad, Wang, Heckman, Ollikainen and Tang. This is an open-access article distributed under the terms of the Creative Commons Attribution License (CC BY). The use, distribution or reproduction in other forums is permitted, provided the original author(s) and the copyright owner(s) are credited and that the original publication in this journal is cited, in accordance with accepted academic practice. No use, distribution or reproduction is permitted which does not comply with these terms. 